\title{
Les pirogues monoxyles du Brivet (Loire-
} Atlantique)

The Brivet dugout canoes (Loire-Atlantique)

\section{Christophe Devals}

\section{OpenEdition}

\section{Journals}

Édition électronique

URL : http://journals.openedition.org/rao/713

DOI : 10.4000/rao.713

ISBN : 978-2-7535-1608-3

ISSN : 1775-3732

\section{Éditeur}

Presses universitaires de Rennes

\section{Édition imprimée}

Date de publication : 20 décembre 2008

Pagination : 305-338

ISBN : 978-2-7535-0789-0

ISSN : 0767-709X

\section{Référence électronique}




\title{
Les pirogues monoxyles du Brivet (Loire-Atlantique)
}

\author{
The Brivet dugout canoes (Loire-Atlantique)
}

\author{
Christophe Devals*
}

\begin{abstract}
Résumé : En 1994 et 1995, un important curage a affecté la rivière Brivet au nord de Pont-Château (Loire-Atlantique), près de Saint-Nazaire. À cette occasion, plus de cinq mille objets archéologiques ont été recueillis, dont cinq cents bois gorgés d'eau. Parmi ces derniers, cinquante-deux pirogues ont été répertoriées dans un état allant de l'exemplaire intact au simple fragment de fond. En 1997, ces embarcations ont fait l'objet d'une étude approfondie qui a permis d'établir un catalogue typologique et technologique inédit pour l'ouest de la France, complété par vingt et une datations (radiocarbone et dendrochronologie), aboutissant aujourd'hui à une synthèse globale sur cet ensemble unique en Europe.
\end{abstract}

Abstract: The Brivet dugout canoes (Loire-Atlantique). In 1994-5, an major dredging was undertaken in the river Brivet, near Pont-Château, NorthEast of Saint-Nazaire (Loire-Atlantique), in South-eastern Brittany. More than 5000 artefacts were uncovered, 500 of them were waterlogged pieces of wood. Among these, 52 dugout canoes have been identified, ranging from an intact one to a simple bottom fragment. In 1997, a special study of these canoes provided a typological and rechnological catalogue, quite new for Western France and completed by 21 dates (radiocarbon and dendrochronology). ranging from Middle Bronze Age to Mediaeval. This leads to a global synthesis for this series, to this day unique in Europe.

Mots clés : pirogue monoxyle, apparaux, aménagements, traces d'outils, carbonisation, curage de rivière, âge du Bronze, âge du Fer, Moyen âge.

Key words: dugout canoe, equipments, fittings, tool traces, carbonization, river dredging, Bronze Age, Iron Age, Mediaeval.

\section{INTRODUCTION}

\section{Historique}

La plus ancienne mention de découverte d'une embarcation monoxyle dans le Brivet date de 1856 lorsqu'en effectuant des travaux de réfection au pont de Méan, en Brière, une barque monoxyle aurait été exhumée du sol tourbeux à 4,50 m de profondeur (Guériff, 1977, p. 19).

À partir de 1874, l'estuaire ancien du Brivet, localisé à l'ouest de l'actuel, est profondément bouleversé par la construction des chantiers navals de Penhouët à SaintNazaire. À cette occasion, des découvertes archéologiques importantes ont lieu, du Néolithique au premier âge du Fer (Kerviler, 1877). Il n'en faut pas plus pour authentifier à l'emplacement même du grand bassin de Penhouët l'antique
Portus Brivates de Ptolémée (Bastard, 1880). Ces fouilles, faites dans des conditions difficiles (il s'agit probablement d'une des toutes premières opérations d'archéologie de sauvetage), livrent un mobilier remarquable empilé dans les vases de l'ancien estuaire, dont la publication exhaustive ne sera réalisée que cent ans plus tard (Vieau, 1982). Malgré sa localisation, ce site n'a livré aucune embarcation.

Après ces découvertes, il faut attendre 1967 pour qu'un curage de faible envergure, réalisé près de la ferme de My dans la partie la plus en amont de la rivière, permette de recueillir la deuxième pirogue monoxyle du Brivet (Bellancourt, 1968). Cette embarcation, très éprouvée par son mode d'extraction de la vase, a été datée par radiocarbone en 1982 (Joncheray, 1986, p. 6, fig. 12). Elle inaugure la série du haut Moyen Âge qui sera extraite, vingt-six ans plus tard, à Drefféac, SainteAnne sur Brivet, Pont-Château et Besné. En 1994 puis 1995

* INRAP (Institut national d'Archéologie préventive), 7 rue de Madrid, Paris - UMR 6173 "Citeres », Université François-Rabelais (Tours). 
en effet, un curage sans précédent sur plus de quinze kilomètres de long est effectué, depuis les marais de Brivé (sic) où la rivière prend sa source jusqu’à la première écluse de Besné, à l'orée de la partie briéronne du Brivet. Pendant quatre années, de 1994 à 1997, le suivi du curage et la prospection des rives puis l'étude finale des bois ont permis de recueillir une série remarquable de pirogues monoxyles, le plus souvent fragmentaires mais parfois entières, qui reste encore à ce jour la plus importante découverte de ce type faite en Europe.

\section{Géographie et hydrographie}

La rivière Brivet, dernier affluent de la Loire en rive droite, court sur près de trente-cinq kilomètres et traverse dix communes dont les plus importantes sont Pont-Château et SaintNazaire (fig. 1). Elle se divise en deux entités géographiques séparées par le goulet rocheux de Pont-Château, lieu de passage obligé et répertorié depuis l'Antiquité au moins (voie romaine Nantes - Vannes). Le secteur au nord de Pont-Château constitue le Bassin du Brivet, vaste étendue de zones marécageuses à travers lesquelles serpente la rivière et d'où sont issues plus des deux tiers des découvertes (fig. 2). La partie méridionale, peu concernée par le curage, alimente la Brière mottière avant de déboucher sur la Loire au niveau de Méan, aujourd'hui un quartier de Saint-Nazaire limitrophe de Penhouët.

Rivière à faible débit d'étiage et très faible pente (quatre mètres sur trente-cinq kilomètres de longueur), le Brivet s'est envasé depuis des millénaires en provoquant un engorgement de son lit qui avait rendu inévitable son curage. Les vases extraites, bien stratifiées, se composaient de trois couches principales : un niveau supérieur très épais de vase noire (ou « fumier lacustre »), très riche en matières organiques et source principale du mobilier archéologique recueilli, un niveau médian constitué de tourbe brune moins organique mais où ont été découvertes certaines pièces parmi les plus anciennes et un niveau inférieur, correspondant à des vases bleues marines quelquefois assez riches en débris organiques d'origine exclusivement naturelle. Ces niveaux étaient d'importance variable selon les endroits alors que le curage, très régulier, n'atteignait pas toujours le fond rocheux et parfois accidenté de la rivière.

\section{LES EMBARCATIONS MONOXYLES}

\section{L'état mécanique et physique des bois}

L'intervention des archéologues s'est effectuée pendant et après le curage; elle a consisté essentiellement à récupérer et préserver le mobilier archéologique considérable que de nombreux riverains avaient déjà recueilli. Parmi toute cette masse documentaire, on a dénombré par la suite plus de cinq cents fragments de bois dont les deux tiers étaient constitués de vestiges de plus de cinquante embarcations monoxyles. Le tiers restant comprenait plusieurs pièces liées à la navigation (pagaies, rames, planchettes...) et des éléments architecturaux (pontons, barrières, passerelles...).

Une bonne moitié des fragments recueillis a subi à des degrés divers un irrémédiable processus de dessèchement à la suite de leur repêchage par les engins de curage; certains, une infime minorité, ont été laissés sur place car ils ne pouvaient plus offrir aucune information. D'autres fragments portaient les stigmates d'un dessèchement ancien consécutif à leur abandon mais ils sont rares. Les pirogues brisées sont nombreuses. Si pour beaucoup il s'agit de dommages anciens, le curage a été très destructeur au début, en particulier pour deux exemplaires représentatifs, Le Port 2 et Tinfois 3. Le premier, manifestement intact, a littéralement éclaté lors de sa découverte et le second a été coupé en deux dans sa partie centrale puis raclé sur une bonne partie de sa longueur par le godet de l'engin de curage. La perte d'informations concernant cette dernière pirogue est considérable car il semble qu'elle ait été abandonnée en cours de fabrication, comme La Soudenais 1 dont il sera question plus loin.

Les coups de foënes ou de crocs sont aussi relativement fréquents (La Soudenais 1 et 6, Catiho 4, Le Prieuré 3, Coët Roz 1 et Marais du Tremble 2). Les autres dégradations observées sont plus anciennes (rayures, fentes, bois rongés par les vers...). Des perforations dues à des insectes comme le lucane cerf-volant ont aussi été remarquées, phénomène peut être antérieur à la fabrication de la pirogue elle-même.

\section{Présentation technologique}

\section{La terminologie}

Les termes utilisés dans l'étude des pirogues monoxyles sont le plus souvent issus du vocabulaire nautique généralement accepté par les spécialistes de la marine en bois (fig. 3). Certains mots sont aujourd'hui abandonnés parce qu'ils sont inadaptés à ce type d'embarcation. Ainsi, par exemple, "tableau arrière " a-t-il remplacé " arcasse ", autrefois utilisé. D'autres sont parfois presque synonymes, comme « ressaut » ou " renfort », la différence étant qu'un ressaut peut-être partout présent dans la pirogue alors qu'un renfort est spécifiquement lié à l'angle formé par un flanc et un fond (bouchain). Enfin, certains termes propres à la marine trouvent leur équivalence exacte dans le vocabulaire quotidien : une gournable, par exemple, est une cheville.

\section{Les datations}

En règle générale, la datation des pirogues est fondé sur le contexte stratigraphique, la morphologie des embarca- 


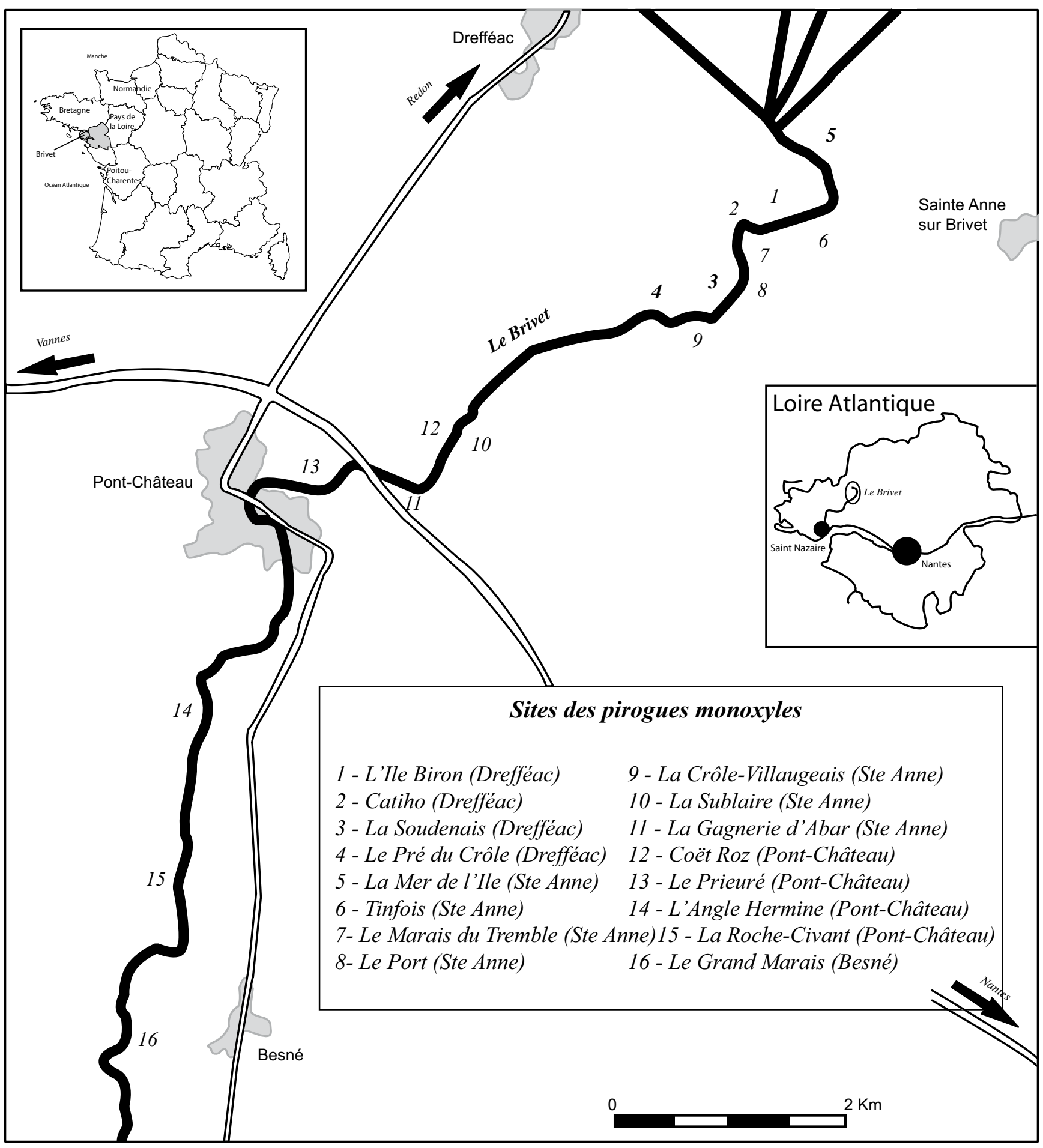

D.A.O.: Sylvie Leray, INRAP, 2007

Figure 1 : Les pirogues du Brivet : localisation des découvertes.

Figure 1: Brivet dugouts: Location maps of discoveries.

tions ou les analyses en laboratoire. La première méthode est sans objet pour ce qui est de la collection du Brivet du fait des conditions de leur repêchage. Il est d'ailleurs assez rare d'avoir l'opportunité de les recueillir dans leur milieu d'ori- gine, même si certains cas sont connus comme les pirogues de Paris-Bercy (Arnold, 1995b).

La morphologie est un indicateur important mais largement insuffisant pour dater : on sait pertinemment que 


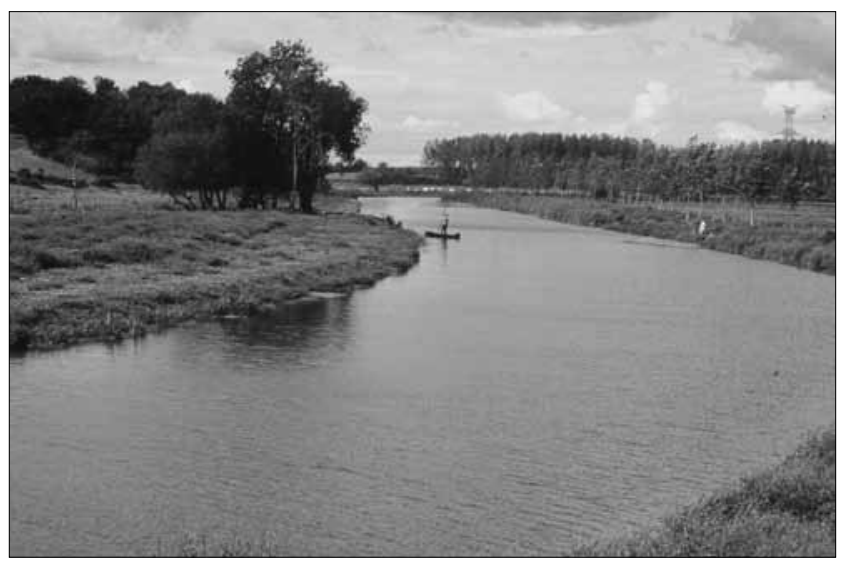

Figure 2 : Le Brivet avec, en arrière-plan à gauche, la butte de Catiho (cf. n 2 fig. 1 ; cl. C. Devals/AFAN, 1995).

Figure 2: Brivet river; in background on the left, the butte de Catiho (cf. $n^{\circ} 2$ fig. 1).

certaines pirogues du Brivet sont médiévales du fait de certains détails techniques propres à cette époque (formes des gradins, par exemple), mais ces cas sont isolés. Même la présence d'un tableau arrière, technique très prisée au Néolithique et à l'âge du Bronze, n'est pas déterminante : des pirogues médiévales en possèdent aussi. Enfin, on peut avoir des surprises comme l'évidement par carbonisation d'une pirogue médiévale, technique reconnue sur le Brivet et procédé jusque-là inédit pour cette période.

La dendrochronologie et le radiocarbone permettent de bien dater les bois si tant est qu'il y ait suffisamment de cernes dans le premier cas et une absence de pollutions extérieures dans le second. Dans le cas du Brivet, ces datations en laboratoire revêtent une importance particulière du fait de l'absence de données stratigraphiques et notamment d'associations céramiques précises. Le coût de ces analyses représente un obstacle de taille et c'est pourquoi à ce jour, seules 21 pirogues ont pu être datées et sont ainsi parfaitement différenciées, au-delà de leurs simples aspects technique ou morphologique (tableau 1). Cependant, 101 prélèvements, dont une quarantaine concernent les pirogues, sont en attente d'un financement nécessaire à leur datation. Les échantillons étudiés ont été choisis selon des critères objectifs, comme leur intérêt scientifique (bois comportant des informations techniques), la géographie (secteurs de concentration), l'état de conservation général et la disponibilité en cernes (ainsi seules La Soudenais 1 et 2 ainsi que L'Île Biron 5 et Le Prieuré 3 possèdent encore une partie de leur aubier, ce qui veut dire que les derniers cernes y sont présents).

\section{Catalogue des pirogues datées}

\section{Les pirogues protohistoriques et gallo-romaines}

L'absence de pirogues antérieures à la fin de l'âge du Bronze est à noter, d'autant que le mobilier daté du Mésolithique ou du Néolithique lato sensu et issu du curage est relativement foisonnant (microlithes, haches, bois travaillés...). On observe aussi une grande rareté du mobilier antique et la seule embarcation datable de cette époque remonte au plus tôt au III $^{\mathrm{e}}$ siècle. La raison en est probablement la remontée progressive des eaux dans la région entre la fin de l'âge

\section{GLOSSAIRE}

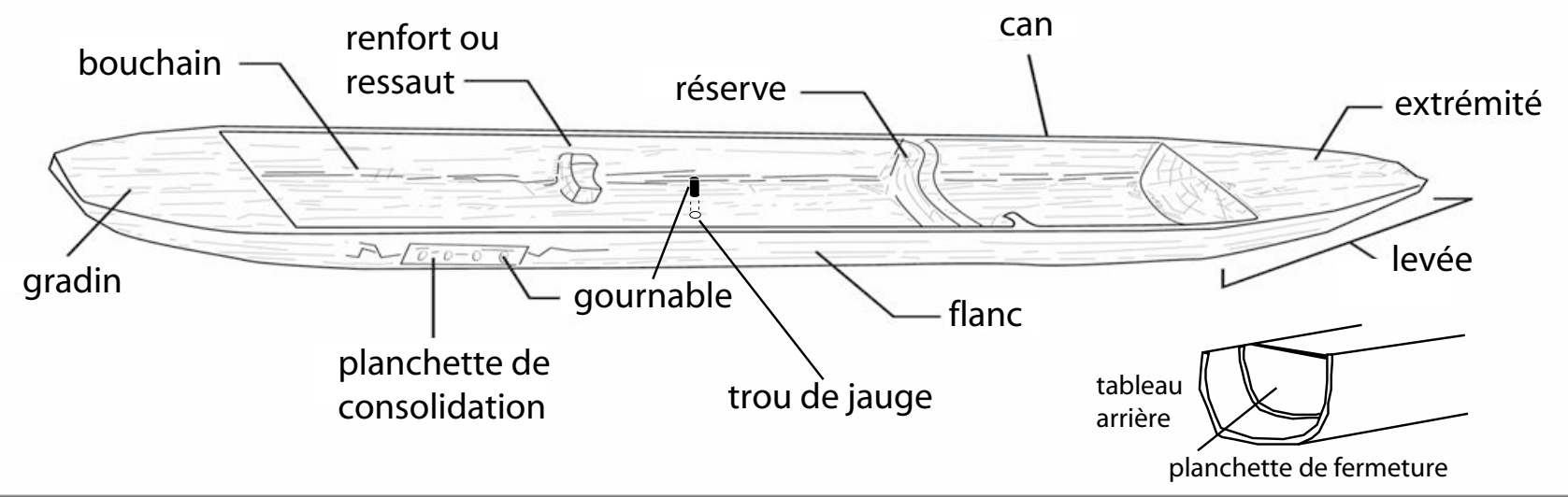

dessin F. Sanz-Pascual, INRAP, 1997 ; D.A.O. S. Leray, INRAP, 2004

Figure 3 : Les principaux termes de charpentage nautique utilisés pour la description des pirogues.

Figure 3: The main nautical carpentry terms used for description of dugouts. 
Tableau 1 : Ensemble des pirogues $\mathrm{du}$ Brivet ayant fait l'objet de prélèvements pour datations radiocarbone et/ou dendrochronologiques (tableau $S$. Leray d'après les données d'O. GirardClos, laboratoire de Chrono-écologie, université de Besançon). Table 1: The Brivet dugouts sampled for radiocarbon and/or dendrochronology dating.

\begin{tabular}{|c|c|c|c|c|c|c|c|c|c|c|}
\hline & $\mathrm{N}^{\circ}$ fig. & Nom & Commune & Inventaire & $\begin{array}{l}\text { dat. } \\
\text { BP }\end{array}$ & & Calibrage & $\mathrm{nbc}$ & Origine & Terminus \\
\hline [a] & 1 & $\begin{array}{c}\text { La Crôle } \\
\text { Villaugeais } 1\end{array}$ & $\begin{array}{c}\text { Sainte Anne sur } \\
\text { Brivet }\end{array}$ & ZM33 009 & 3180 & 55 & $\begin{array}{c}{[1595-1307]} \\
\text { BC } \\
\end{array}$ & 62 & & \\
\hline [b] & & $\begin{array}{c}\text { Le Pré du Crôle } \\
1\end{array}$ & Drefféac & $\mathrm{Zl} 42001$ & 2955 & 50 & $\begin{array}{c}{[1311-1002]} \\
\text { BC }\end{array}$ & 40 & & \\
\hline$[\mathrm{c}]$ & 3 & $\begin{array}{c}\text { La Crôle } \\
\text { Villaugeais } 2 \\
\end{array}$ & $\begin{array}{c}\text { Sainte Anne sur } \\
\text { Brivet } \\
\end{array}$ & ZM33 020 & 2455 & 50 & {$[7646406] \mathrm{BC}$} & 34 & & \\
\hline [d] & 6 & Tinfois 2 & $\begin{array}{c}\text { Sainte Anne sur } \\
\text { Brivet }\end{array}$ & $\mathrm{ZO} 32017$ & 2285 & 45 & $|401-202| \mathrm{BC}$ & 66 & & \\
\hline$[\mathrm{e}]$ & 2 & L'Ile Biron 1 & Drefféac & ZC11001 & 2265 & 45 & {$[394-201] \mathrm{BC}$} & 71 & & \\
\hline [f] & 4 & Tinfois 3 & $\begin{array}{c}\text { Sainte Anne sur } \\
\text { Brivet }\end{array}$ & ZO32018 & 2070 & 55 & $\begin{array}{c}{[350-60]} \\
\mathrm{BC} / \mathrm{AD}\end{array}$ & $<50$ & & \\
\hline [g] & 5 & La Sublaire 1 & $\begin{array}{c}\text { Sainte Anne sur } \\
\text { Brivet }\end{array}$ & H2 001 & 1640 & 45 & {$[260-540] \mathrm{AD}$} & $<50$ & & \\
\hline [h] & 10 & La Soudenais 3 & Drefféac & ZH39d 051 & 1545 & 45 & {$[425-614] \mathrm{AD}$} & 63 & & \\
\hline [i] & 11 & Le Port 5 & $\begin{array}{c}\text { Sainte Anne sur } \\
\text { Brivet } \\
\end{array}$ & ZO1 099 & 1525 & 45 & {$[437-630] \mathrm{AD}$} & 160 & & \\
\hline [j] & 9 & Le Port 6 & $\begin{array}{c}\text { Sainte Anne sur } \\
\text { Brivet }\end{array}$ & ZO1 100 & 1285 & 40 & {$[650-820] \mathrm{AD}$} & 24 & & \\
\hline [k] & 7 & La Soudenais 2 & Drefféac & ZH39d 050 & 1175 & 45 & {$[729-985]$ AD } & 30 & & \\
\hline$[1]$ & 8 & La Soudenais 6 & Drefféac & ZH39d 088 & 1150 & 40 & {$[780-980] \mathrm{AD}$} & 15 & & \\
\hline$[\mathrm{m}]$ & 12 & La Soudenais 1 & Drefféac & ZH39d 001 & 1073 & 40 & $\begin{array}{c}{[870-1025]} \\
\mathrm{AD}\end{array}$ & $<50$ & & \\
\hline [n] & 13 & Le Port 4 & $\begin{array}{c}\text { Sainte Anne sur } \\
\text { Brivet }\end{array}$ & ZO1 098 & 1045 & 40 & $\begin{array}{c}{[892-1151]} \\
\mathrm{AD}\end{array}$ & 90 & 942 & 1031 \\
\hline [o] & 14 & Le Port 8 & $\begin{array}{c}\text { Sainte Anne sur } \\
\text { Brivet } \\
\end{array}$ & ZO1 103 & & & & 60 & 949 & 1008 \\
\hline [p] & 15 & $\begin{array}{c}\text { L'Angle } \\
\text { Hermine } 2\end{array}$ & Pont-Château & ZW138d 004 & 1000 & 40 & $\begin{array}{c}960-1160] \\
A D \\
\end{array}$ & $<50$ & & \\
\hline [q] & 16 & $\begin{array}{c}\text { La Crôle } \\
\text { Villaugeais } 3 \\
\end{array}$ & $\begin{array}{c}\text { Sainte Anne sur } \\
\text { Brivet }\end{array}$ & $\begin{array}{c}\text { ZM33 } 043 \text { et } \\
055 \\
\end{array}$ & & & & 62 & 962 & 1023 \\
\hline$[\mathbf{r}]$ & 17 & $\begin{array}{c}\text { La Roche Civant } \\
1\end{array}$ & Pont-Château & YO103 014 & $\begin{array}{l}1000 \\
955 \\
930\end{array}$ & $\begin{array}{l}45 \\
40 \\
45\end{array}$ & $\begin{array}{c}{[975-1164]} \\
\text { AD } \\
{[1013-1181]} \\
\text { AD } \\
{[1024-1212]} \\
\text { AD }\end{array}$ & 126 & 1015 & 1140 \\
\hline$[\mathrm{s}]$ & & Le Prieuré 2 & Pont-Château & AH26 003 & 960 & 40 & $\begin{array}{c}{[1000-1170]} \\
\mathrm{AD}\end{array}$ & $<50$ & & \\
\hline$[t]$ & 18 & Le Port 1 & $\begin{array}{c}\text { Sainte Anne sur } \\
\text { Brivet }\end{array}$ & ZO1 012 & 950 & 45 & $\begin{array}{c}{[1014-1199]} \\
\mathrm{AD}\end{array}$ & 39 & & \\
\hline [u] & 19 & Le Port 2 & $\begin{array}{c}\text { Sainte Anne sur } \\
\text { Brivet }\end{array}$ & ZO1 020 & 751 & 40 & $\begin{array}{c}{[1190-1300]} \\
\mathrm{AD}\end{array}$ & $<50$ & & \\
\hline
\end{tabular}

Tableau Sylvie Leray, Inrap, d'après les données de Olivier Girard-Clos, Laboratoire de chrono-écologie, Université de Besançon

du Fer et le Bas-Empire, phénomène dû aux transgressions flandriennes qui ont concerné la Brière et la vallée du Brivet au même titre que le littoral du pays guérandais et nazairien (Visset, 1990).

[a] - La Crôle-Villaugeais 1, Sainte Anne sur Brivet : inv. ZM.33.009 (datations ${ }^{14} \mathrm{C}: 1595-1307$ BC et $1430-1115$ BC; fig. $4 \mathrm{n}^{\circ} 1$; fig. 5).

Cet exemplaire, probablement monoxyle, est le plus ancien découvert dans les vases du Brivet (âge du Bronze final). Très fragmentaire, il est constitué de trente fragments constituant la partie arrière de la pirogue et notamment le tableau. Cette double réserve transversale destinée à accueillir une planchette de fermeture est paradoxalement très bien conservée et la planchette en demi-lune, riche en traces d'outils, est intacte. La partie conservée n'a plus que $1 \mathrm{~m}$ de longueur pour $0,70 \mathrm{~m}$ de large. Il s'agit d'une embarcation de type semi-cylindrique respectant la forme du tronc dans lequel elle a été taillée. Trois ouvertu- res obliques sont percées dans le bouchain tribord et leur fonction n’est pas déterminée.

[b] - Le Pré du Crôle 1, Drefféac : inv. ZI42.001 (datation ${ }^{14} \mathrm{C}: 1311-1002 \mathrm{BC}$; non figuré).

Cet ensemble comprend sept fragments formant deux flancs - fonds et peut-être un bouchain Le plus important des fragments mesure $1,10 \mathrm{~m}$ de longueur pour $0,25 \mathrm{~m}$ de largeur. Deux orifices faits de main d'homme ont été observés. L'état des bois n'a pas permis d'en faire un relevé et un des fragments a été sacrifié pour la datation. Il s'agit néanmoins de la deuxième plus ancienne pirogue du Brivet.

[c] - La Crôle-Villaugeais 2, Sainte Anne sur Brivet: inv. ZM.33.020 (datation ${ }^{14} \mathrm{C}$ : 764-406 BC; fig. $4 \mathrm{n}^{\circ} 3$; fig. 6).

Seul monoxyle d'Europe daté du Hallstatt, cette pirogue est aussi la plus longue de celles recueillies dans les eaux du Brivet puisqu'elle dépasse $7 \mathrm{~m}$ sans que ses extrémités 


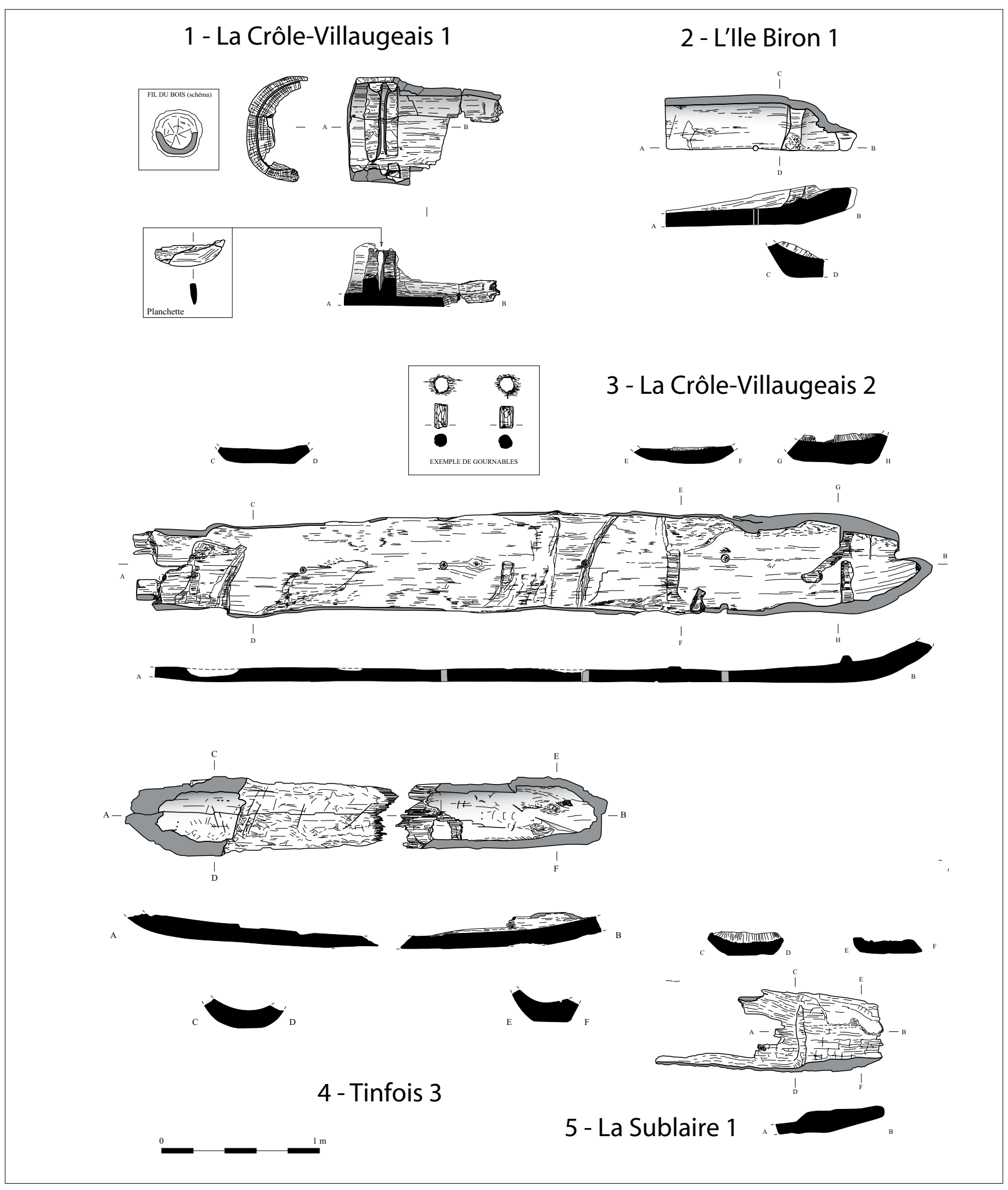

Figure 4 : Fragments de pirogues datés - Protohistoire et Gallo-romain (cf. tabl. 1).

Figure 4: Dated dugout fragments - Protohistory and Gallo-Roman (see tabl. 1). 


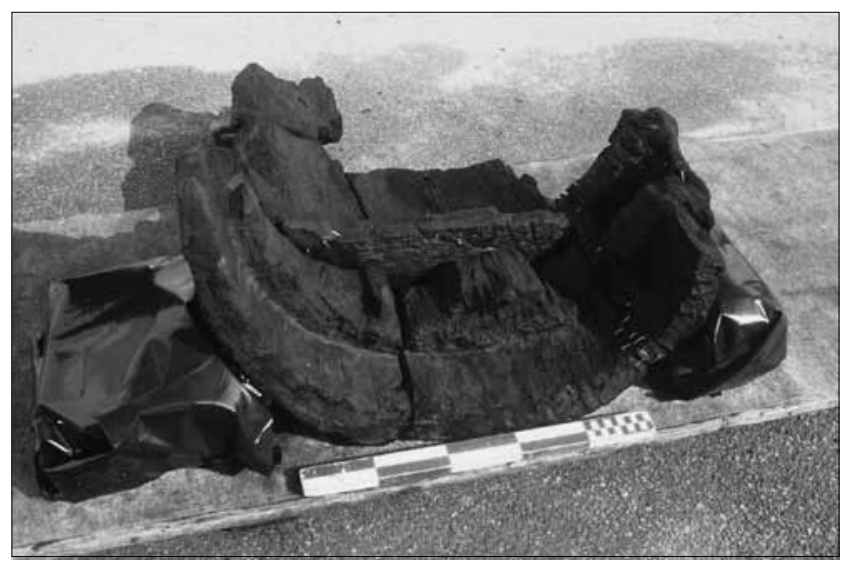

Figure 5 : La Crôle-Villaugeais 1 : tableau arrière de la pirogue avec planchette de fermeture encore en place (cl. C. Devals/AFAN, 1995).

Figure 5: La Crôle-Villaugeais 1 dugout: stern with closing board still in place.

ne nous soient parvenues, pour une largeur conservée de $0,65 \mathrm{~m}$. Les bouchains ont des angles de 155 à $160^{\circ}$. Les amorces de levées sont perceptibles et le fond plat est complet, doté de six trous de jauge d'épaisseur (diamètre moyen de 0,4 à $0,5 \mathrm{~cm}$ ) et de réserves transversales très érodées. Il est donc possible qu'il s'agisse d'une pirogue utilisée sur un temps assez long. Les flancs sont absents, arrachés anciennement, mais cette embarcation a aussi beaucoup souffert de son extraction des vases car elle est très fragilisée en son milieu. Quatre des six trous de jauge possèdent encore leurs gournables en frêne dont trois sont de section polygonale à larges facettes et une cylindrique.

[d] - Tinfois 2, Sainte Anne sur Brivet : inv. ZO32.017 (datation ${ }^{14} \mathrm{C}$ : 401-202 BC; fig. $7 \mathrm{n}^{\circ}$ 6).

Douze éléments appartiennent probablement à cette pirogue mais un seul est étudiable. Long de 2,36 m pour une largeur maximale de $0,84 \mathrm{~m}$, il s'agit d'un fond avec deux bouchains et un départ de flanc (épaisseur : $2,5 \mathrm{~cm}$ ). Les angles des deux bouchains sont différents, l'un étant de 110 à $120^{\circ}$, l'autre de 120 à $125^{\circ}$. Le profil bâbord / tribord n'a pas sa hauteur complète et on note un départ de levée à l'extrémité (hauteur conservée : 0,13 m). De nombreux nœuds sont présents d'une extrémité à l'autre. Le cœur de l'arbre utilisé apparaît désaxé par rapport au centre de la pirogue, le fil du bois indiquant le centre du tronc près d'un des bouchains. Les onze autres fragments forment trois ensembles : un premier lot avec trois fragments jointifs, un deuxième avec quatre fragments jointifs (dont un fragment de fond avec bouchain partiel), un troisième enfin avec aussi quatre fragments jointifs.

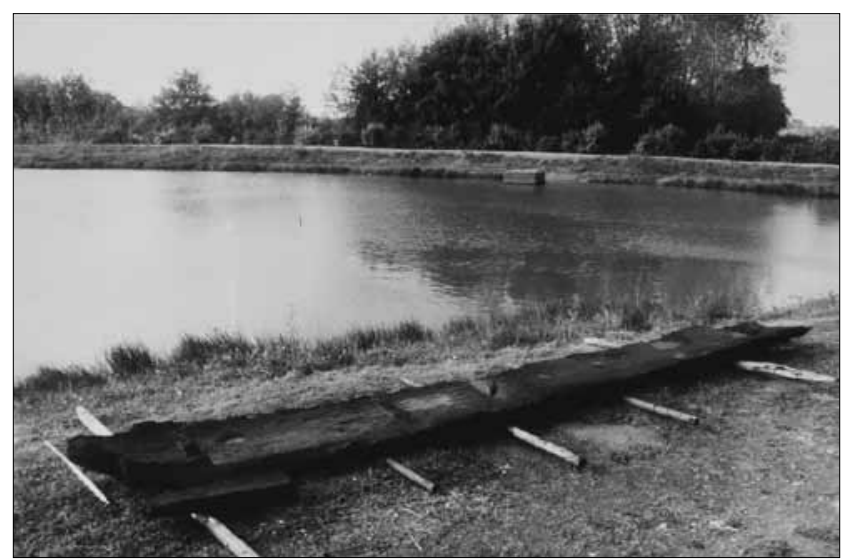

Figure 6 : La grande pirogue hallstattienne La Crôle-Villaugeais 2 (cl. C. Devals/AFAN, 1995).

Figure 6: La Crôle-Villangeais 2 large Hallstatt dugout.

[e] - Lîle Biron 1, Drefféac: inv. ZC11.001 (datation ${ }^{14} \mathrm{C}$ : 394-201 BC; fig. $4 \mathrm{n}^{\circ} 2$ ).

Il s'agit d'une extrémité dont la forme du bec n'est pas déterminée. Le fragment est long de $1,20 \mathrm{~m}$ pour $0,37 \mathrm{~m}$ de large. Le fond est plat et le bouchain arrondi (angle de $125^{\circ}$ au niveau du corps central) mais les flancs ne sont pas conservés. Cette pirogue est dotée d'une réserve transversale au niveau du départ de la levée.

[f] - Tinfois 3, Sainte Anne sur Brivet inv. ZO32.018 (datation ${ }^{14} \mathrm{C}: 350 \mathrm{BC}-60 \mathrm{AD}$; fig. $4 \mathrm{n}^{\circ} 4$ ).

De cette pirogue, seul le fond en deux morceaux nous est parvenu, mais il est presque complet car les départs des levées sont bien visibles de part et d'autre. Longue de 2,88 $\mathrm{m}$ et large de $0,50 \mathrm{~m}$, elle présente une épaisseur du fond parfois importante $(0,10 \mathrm{~m})$. Son intérêt réside principalement dans l'abondance des empreintes de travail (fig. 8) qui offrent probablement le modus operandi des charpentiers gaulois qui l'ont réalisée : en partant à reculons à partir de chacune des extrémités du bateau lors des travaux de finition à l'herminette dont l'une était probablement ébréchée.

[g] - La Sublaire 1, Sainte Anne sur Brivet : inv. H2.001 (datation ${ }^{14} \mathrm{C}: 260-540 \mathrm{AD}$; fig. $4 \mathrm{n}^{\circ}$ 5).

Il s'agit d'un gradin et d'une partie du fond d'une pirogue assez desséchée. L'extrémité est rectangulaire mais le ressaut du gradin est oblique, peu prononcé. Cette pirogue typologiquement banale est la seule des embarcations datées qui pourrait être de la période gallo-romaine. 


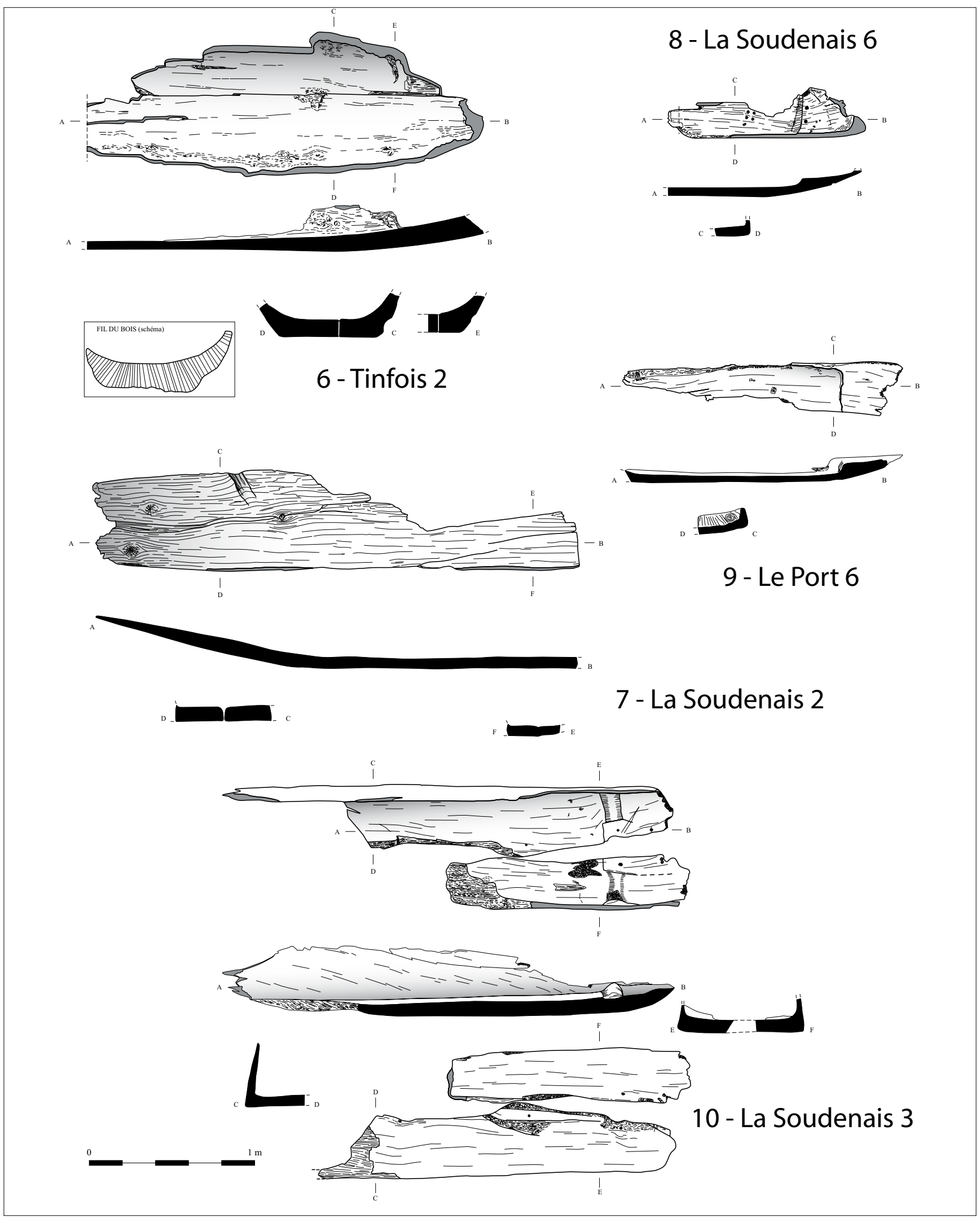

Figure 7 : Fragments de pirogues datés - Âge du Fer et haut Moyen Âge (cf. tabl. 1). Figure 7: Dated dugout fragments - Iron Age and Early Middle Age (see tabl. 1). 


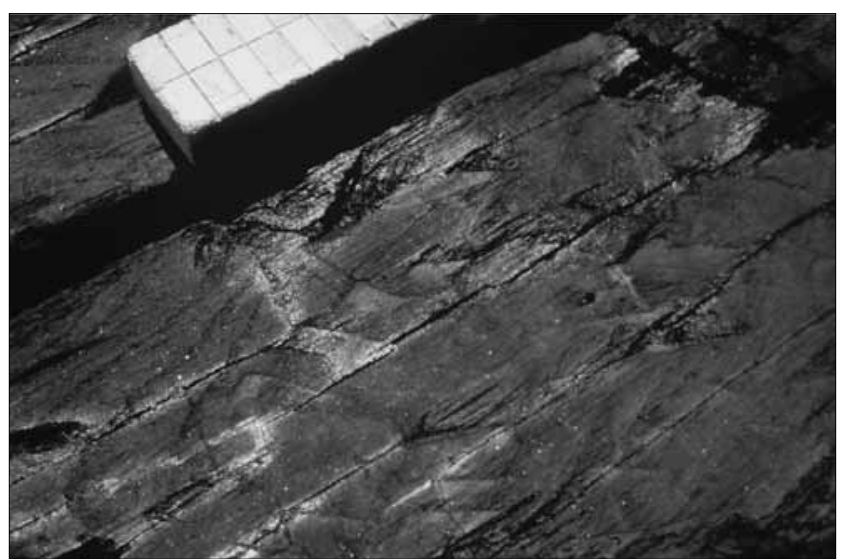

Figure 8 : Détail des empreintes d'herminette visibles sur le fond interne de la pirogue gauloise Tinfois 3 (cl. C. Devals/AFAN, 1995). Figure 8: Detail of adze marks on the internal bottom of the Gaulish Tinfois 3 dugout.

\section{Les pirogues de l'Antiquité tardive au XIII siècle}

[h] - La Soudenais 3, Drefféac : inv. ZH39d.051 (datation ${ }^{14} \mathrm{C}: 425-614 \mathrm{AD}$; fig. $7 \mathrm{n}^{\circ} 10$ ).

Cette pirogue a été recueillie en deux grands fragments disjoints et pourrait avoir été détruite au moment de sa sortie des vases (cassures fraîches). Sa longueur conservée est de $2,75 \mathrm{~m}$ et sa largeur de $0,74 \mathrm{~m}$ pour une hauteur maximale de 0,42 m. Les flancs, assez fins, sont un peu rentrants sur la partie supérieure de l'embarcation et amincis à hauteur du can, phénomène probablement lié à une usure et à un dessèchement anciens. Le fond est plat et relativement épais $(0,13 \mathrm{~m}$ en moyenne). Sur la face interne du fond, on note une entaille à mi-bois au niveau de la levée, façonnée de manière à recevoir une planchette (disparue). Quatre gournables, partiellement préservées, maintenaient cette planchette de réparation ou de consolidation. Au même niveau, mais sur la face externe, existait une seconde planchette pour laquelle un seul trou de fixation est encore visible. Ces deux installations sont peut-être contemporaines et indiquent une grande fragilisation de l'embarcation. L'état d'usure de l'ensemble signifie cependant une utilisation sur un temps relativement long, privilégiant donc une réparation a posteriori. Aucune trace de calfatage n'est par contre observée.

Les éléments de confort de cette pirogue se limitent apparemment à des renforts situés à la base de la levée et qui ont pu servir de "cale-pieds». Son état fragmentaire ne permet pas d'affirmer qu'il s'agit d'une pirogue symétrique bien qu'elle semble typologiquement appartenir à cette catégorie.

[i] - Le Port 5, Sainte-Anne sur Brivet : inv. Z01.099 (datation ${ }^{14} \mathrm{C}$ : 437-630 AD; fig. $9 \mathrm{n}^{\circ} 11$; fig. 10).
Cet exemplaire taillé dans un chêne très effilé présente une longueur conservée de $3,72 \mathrm{~m}$ pour une largeur d'à peine $0,45 \mathrm{~m}$ et une hauteur maximale de $0,24 \mathrm{~m}$ (angle du bouchain $90^{\circ}$ ). Les flancs ont en effet presque complètement disparu, mais anciennement. Ici, le curage n'a été destructeur que sur une des extrémités dont le départ de la levée reste néanmoins perceptible en profil. Cette constatation permet d'envisager une longueur totale initiale de $4 \mathrm{~m}$ environ. Sa brisure longitudinale est aussi consécutive au mode de repêchage. Avec son fond plat très épais $(0,19 \mathrm{~m})$, elle rappelle beaucoup La Soudenais 1 (voir infra [m]) et les raisons en sont peut-être similaires. Outre sa levée marquée par un seuil la faisant vraiment ressembler à un bateau, un ressaut transversal partiellement conservé a pu être réservé au moment de sa taille pour consolidation. Aucun autre aménagement n’a été relevé.

[j] - Le Port 6, Sainte-Anne sur Brivet : inv. Z01.100 (datation ${ }^{14} \mathrm{C}: 650-820 \mathrm{AD}$; fig. 7 n ${ }^{\circ}$ ).

Très fragmentaire, cette pirogue a néanmoins livré quelques informations intéressantes. Les trois éléments qui en proviennent ne sont pas jointifs et seul le plus grand est directement identifiable comme appartenant à une pirogue monoxyle. Long de 1,68 $\mathrm{m}$ et large au mieux de $0,32 \mathrm{~m}$ pour une hauteur conservée d'à peine $0,09 \mathrm{~m}$ au niveau de son gradin, ce monoxyle en chêne a perdu anciennement la majeure partie de ses flancs et seuls les bouchains sont encore visibles au contact du fond et de l'emmarchement du gradin. Le fond est plat, assez fin, mais irrégulièrement fini et son extrémité conservée est sévèrement rognée par l'usure naturelle du bois. Un processus de dessèchement entamé à la suite du curage ne permet pas d'y relever des indices d'utilisation mais la partie externe du fond est suffisamment lisse pour envisager que cette pirogue n'ait pas navigué bien longtemps. Dans la contremarche du gradin, on note une perforation dont la fonction échappe. Enfin, des rayures anciennes sont visibles sur la face externe du monoxyle.

[k] - La Soudenais 2, Drefféac : inv. ZH39d.050 (datation ${ }^{14} \mathrm{C}$ : 729-985 AD; fig. $7 \mathrm{n}^{\circ} 7$ ).

Cet exemplaire représente sans doute un des monoxyles les plus originaux de toute la série par son profil extrêmement élancé, conservé sur un tiers à la moitié de sa longueur qui atteint encore 2,98 m pour une largeur importante de $0,61 \mathrm{~m}$ et une hauteur préservée de $0,31 \mathrm{~m}$. Sa levée est sans gradin, aussi fine que le fond (épaisseur maximale $0,10 \mathrm{~m}$ ) mais les flancs ont complètement disparu. Taillée dans un chêne très noueux conservant encore quelques résidus d'aubier, cette pirogue ne dispose d'aucun aménagement à l'exception d'une petite perforation à l'extrémité de la levée, qui a pu servir à accrocher un filet ou tout autre matériel de pêche. 


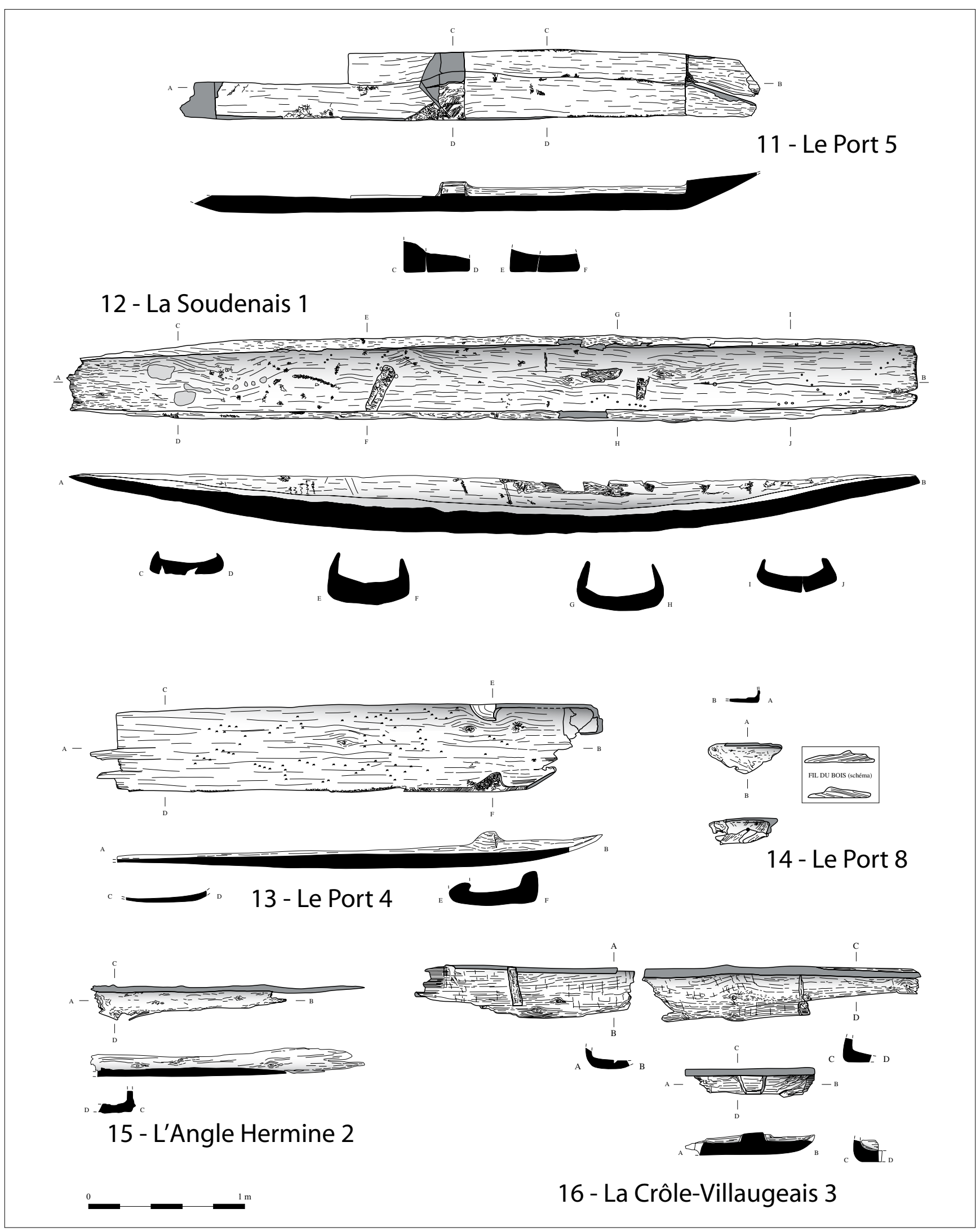

Figure 9 : Pirogues et fragments - Antiquité à Moyen Âge. Figure 9: Dugouts and fragments - Antiquity to Middle Ages. 


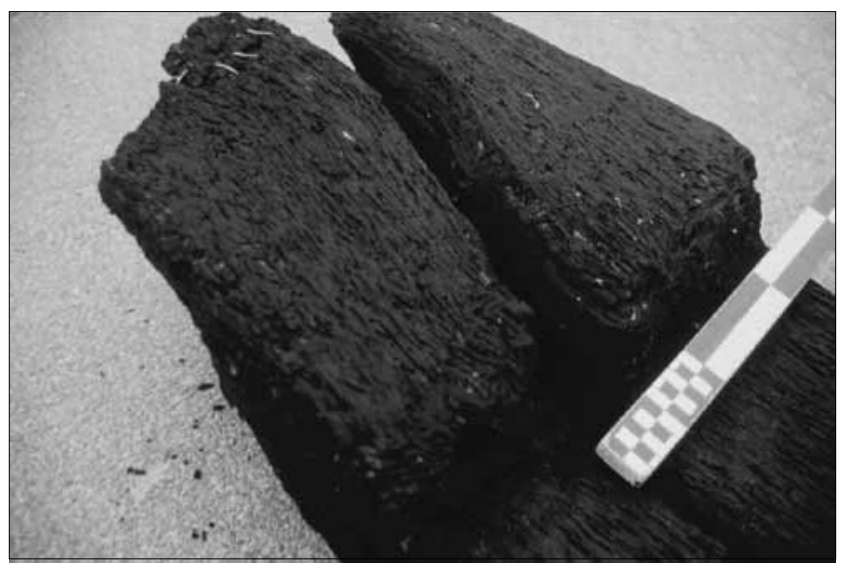

Figure 10 : Détail du gradin de la pirogue mérovingienne Le Port 5 ( cl. C. Devals/AFAN, 1995).

Figure 10: Detail of the stage of the Merovingian Le Port 5 dugout.

[1] - La Soudenais 6, Drefféac : inv. ZH39d.088 (datation ${ }^{14} \mathrm{C}$ : 780-980 AD; fig. 7 n 8 ).

Dans un état de conservation assez voisin de celui de $L e$ Port 6 [j], ce monoxyle ne conserve qu'un fragment de fond et d'une des levées avec départs des flancs. Sa longueur est de $1,20 \mathrm{~m}$ pour une largeur de $0,30 \mathrm{~m}$ et une hauteur de $0,15 \mathrm{~m}$. Taillée dans un chêne assez noueux, cet exemplaire a beaucoup souffert du curage car la plupart des cassures sont fraîches. Les bouchains forment un angle droit ouvrant sur des flancs qui devaient être assez fins. Deux trous circulaires apparaissent encore à l'arrière du gradin; creusés au foret à cuiller, ils devaient supporter un aménagement particulier demeuré inconnu. Il est possible que ces perforations aient été effectuées tardivement et concrétisent donc un ajout au monoxyle de base. Un fragment de gournable en bois blanc taillée en facettes a pu être recueilli dans l'une des perforations. Enfin, cinq autres perforations régulières établies en deux lignes parallèles, visibles sur le fond, sont probablement la conséquence de deux coups consécutifs portés par une foëne.

[m] - La Soudenais 1, Drefféac: inv. ZH39d.001 (datation ${ }^{14} \mathrm{C}$ : 870-1025 AD; fig. $9 \mathrm{n}^{\circ} 12$; fig. 11).

$C$ 'est la pirogue la mieux conservée de l'ensemble issu du Brivet, toutes périodes confondues. Son extraction des vases d'ailleurs a été à l'origine du déclenchement de l'opération de sauvetage archéologique. Ce monoxyle est taillé dans un chêne noueux dont l'aubier est partiellement conservé de part et d'autre des flancs. Le diamètre du fût initial est donc à peu près restituable $(0,55$ à $0,60 \mathrm{~m})$. Il s'agit d'un exemplaire parfaitement symétrique dont la longueur atteint $5,45 \mathrm{~m}$ pour $0,55 \mathrm{~m}$ de largeur et $0,35 \mathrm{~m}$ de hauteur. L'épaisseur $\mathrm{du}$ fond est de $0,15 \mathrm{~m}$ et rend l'embarcation assez massive malgré son aspect longiligne.

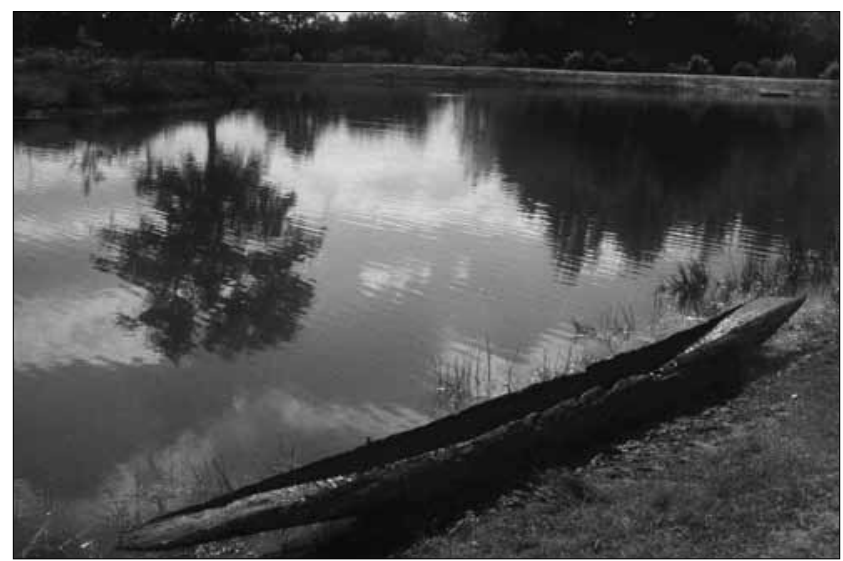

Figure 11 : La grande pirogue carolingienne La Soudenais 1, extrêmement profilée (cl. C. Devals/AFAN, 1995).

Figure 11: The large and very streamlined Carolingian dugout La Soudenais 1.

Outre des impacts "récents " (coups de fouënes, petites rayures), La Soudenais 1 présente de nombreuses empreintes d'outils et des traces de carbonisation, pratiquées avant le passage d'outils de taille, sur une de ses extrémités. Il s'agit d'indices majeurs signifiant que cette pirogue n'a probablement jamais été achevée. En effet, les traces d'outils sont celles des herminettes qui ont servi à creuser le tronc avant finition et se retrouvent sur tout le fond interne. Ces témoignages technologiques sont fragiles et disparaissent vite lors de l'utilisation même courte d'une pirogue, surtout sur le fond interne de celle-ci.

Le procédé de carbonisation, utilisé en parallèle, permet un évidement du fût en pratiquant une saignée longitudinale par étapes successives à l'aide de foyers entretenus et contrôlés d'un bout à l'autre de la chaîne opératoire. Déjà signalée plusieurs fois sur des monoxyles du Néolithique et de l'âge du Bronze, c'est la première fois que cette technique est reconnue pour le Moyen Âge.

Même si elles suffisent à indiquer l'abandon précoce de l'embarcation, ces traces ne sont pas les seuls indices en faveur de cette interprétation. On note aussi deux longues fentes longitudinales sur le fond de la pirogue. Ces fentes, probablement consécutives à un mauvais séchage, ont pu être trop importantes pour qu'on tente de les réparer à l'aide de planchettes. Ainsi, le fût a-t-il été abandonné en l'état, ce qui expliquerait aussi l'épaisseur beaucoup trop importante du fond. En effet, une telle masse de bois conservée aurait déséquilibré l'embarcation. Enfin, l'absence totale d'aménagements (réserves, renforts) et la trop petite hauteur des flancs internes vont aussi dans ce sens.

Il est possible que, s'apercevant du mauvais état du bois, le charpentier ait abandonné le monoxyle en cours de finition et qu'il l'ait coulé à proximité de son chantier de construction. Sa masse, qui l'aura ensuite protégé des vicissitudes 
du temps, explique sans doute aussi qu'elle ait été extraite intacte de la rivière malgré la violence du curage.

[n] - Le Port 4, Sainte-Anne sur Brivet : inv. Z01.098 (dendrochronologie : 942-1031 AD, datation ${ }^{14} \mathrm{C}$ : 892$1151 \mathrm{AD}$; fig. $\left.9 \mathrm{n}^{\circ} 13\right)$.

Autre exemplaire remarquable, Le Port 4 est brisé mais sa longueur atteint encore $3,32 \mathrm{~m}$ pour une largeur de $0,56 \mathrm{~m}$ et une hauteur de $0,23 \mathrm{~m}$, les flancs n'étant pas conservés. Dotée de ressauts en forme d'ailerons au niveau du départ de la levée, cette pirogue possède à son extrémité l'empreinte d'une planchette de consolidation ou de réparation, aujourd'hui disparue mais qui a protégé de nombreuses traces d'herminette (fig. 12), témoignages de l'évidement et de la finition. Son fond, dont le profil externe apparaît légèrement incurvé, est extrêmement fin dans sa partie centrale. C'est d'ailleurs à ce niveau que le godet de la drague l'a probablement brisée, les traces de cassures fraîches étant nombreuses (fond, flancs, extrémités). Enfin, de nombreux impacts de fouënes sont visibles sur la face interne.

[o] - Le Port 8, Sainte-Anne sur Brivet : inv. ZO1.103 (dendrochronologie : 949-1008 AD; fig. $9 \mathrm{n}^{\circ} 14$ ).

Bien que l'ensemble restituable de cette pirogue ne dépasse pas $0,46 \mathrm{~m}$ de long pour $0,19 \mathrm{~m}$ de large, elle se compose de deux lots de respectivement neuf et sept fragments de bois. Le second permet de reconstituer une levée dotée d'une perforation (gournable absente). Le bouchain a un angle de $90^{\circ}$. D'après l'orientation du fil du bois, oblique par rapport au fond sur l'extérieur du flanc, on peut replacer symétriquement les deux ensembles à tribord et bâbord, formant ainsi un élément de levée.

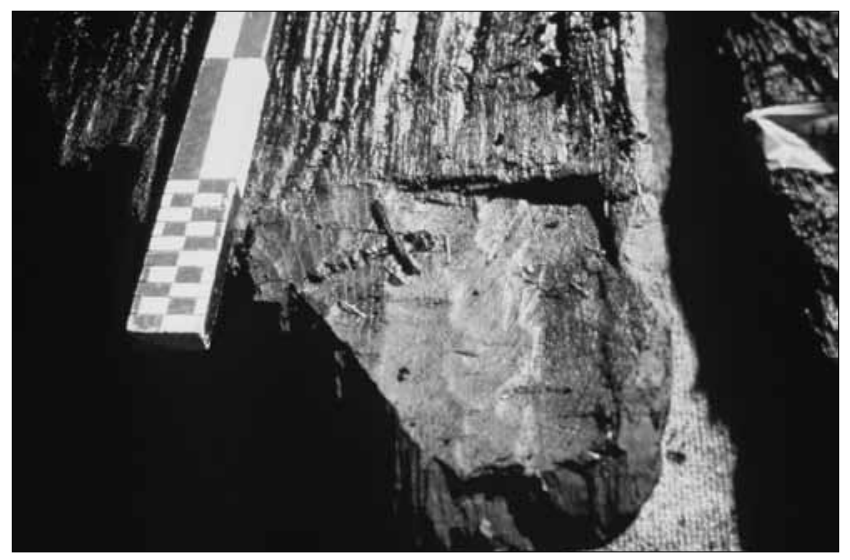

Figure 12 : Traces d'outils visibles à l'emplacement d'une planchette de réparation disparue sur l'extrémité conservée de la pirogue Le Port 4 (cl. C. Devals/AFAN, 1997).

Figure 12: Toolmarks preserved under a lost repair board, on the preserved end of Le Port 4 dugout. [p] - L'Angle Hermine 2, Pont-Château : inv. ZW138d.004 (datation ${ }^{14} \mathrm{C}: 960-1160 \mathrm{AD}$; fig. $9 \mathrm{n}^{\circ} 15$ ).

Les deux fragments dessinés appartiennent à la même embarcation mais ne sont pas jointifs (un troisième fragment pourrait s'y associer). Le plus grand est un morceau de fond long de 3,56 m pour une largeur de 0,40 m (angle du bouchain $95^{\circ}$ ). Le plus court atteint $1,23 \mathrm{~m}$ mais n'est large que de $0,02 \mathrm{~m}$ (angle du bouchain 90 à $95^{\circ}$ ). Ces pièces sont desséchées voire déformées. Les nœuds sont nombreux et proéminents et le façonnage est relativement grossier. Trois perforations sont observables sur le plus grand des fragments mais les gournables sont absentes.

[q] - La Crôle Villaugeais 3, Sainte-Anne sur Brivet : inv. ZM33.043 et 055 (dendrochronologie : 962-1023 AD; fig. $\left.9 \mathrm{n}^{\circ} 16\right)$.

Trois fragments non jointifs constituent les restes de cette embarcation très abîmée, retrouvée tardivement dans les vases extraites du Brivet et donc partiellement desséchée. Taillée dans un chêne assez noueux, elle présente des vestiges de renforts au niveau du fragment de levée conservé. Ses flancs, brisés lors du repêchage, sont très peu conservés mais permettent de constater un profil légèrement rentrant, probablement dû à la forme de l'arbre. On peut ajouter que cette pirogue a pu être authentifiée comme telle en y associant un autre fragment lui-même isolé.

[r] - La Roche-Civant 1, Pont-Château : inv. YO103.014 (dendrochronologie : 1015-1140 AD, datations ${ }^{14} \mathrm{C}$ : 975$1164 \mathrm{AD}, 1013-1181 \mathrm{AD}, 1024-1212 \mathrm{AD}$; fig. $\left.13 \mathrm{n}^{\circ} 17\right)$.

Cet exemplaire est certainement l'un des plus fragmentés de la série du Brivet puisque dix-neuf éléments le composent. Le remontage a permis de sérier trois lots non jointifs plus un élément isolé, mais appartenant tous à la même embarcation. L'élément isolé est un petit fragment de fond avec son flanc (can conservé) et un renfort latéral bien abîmé. Le lot 1 s'associe au premier fragment mais sans ressaut latéral. Le lot 2 intègre un élément de levée en plus du fond et du flanc. Le lot 3 n'est qu'un fragment de fond doté d'une levée mais sans can conservé. La " restitution » de l'ensemble donnerait une longueur conservée de 2,05 m pour $0,29 \mathrm{~m}$ de large avec une hauteur maximale de $0,31 \mathrm{~m}$. Des traces d'outils sont perceptibles sur le fragment isolé et sur le bouchain du lot 2. Le lot 3, sur la partie creusée de la levée, garde les traces d'une réparation de forme rectangulaire avec des fragments des gournables utilisées pour maintenir les éléments réparés entre eux. Cet ensemble était si fragmenté que trois datations par radiocarbone ont été faites, indiquant finalement l'appartenance des différents échantillons à la même pirogue. 


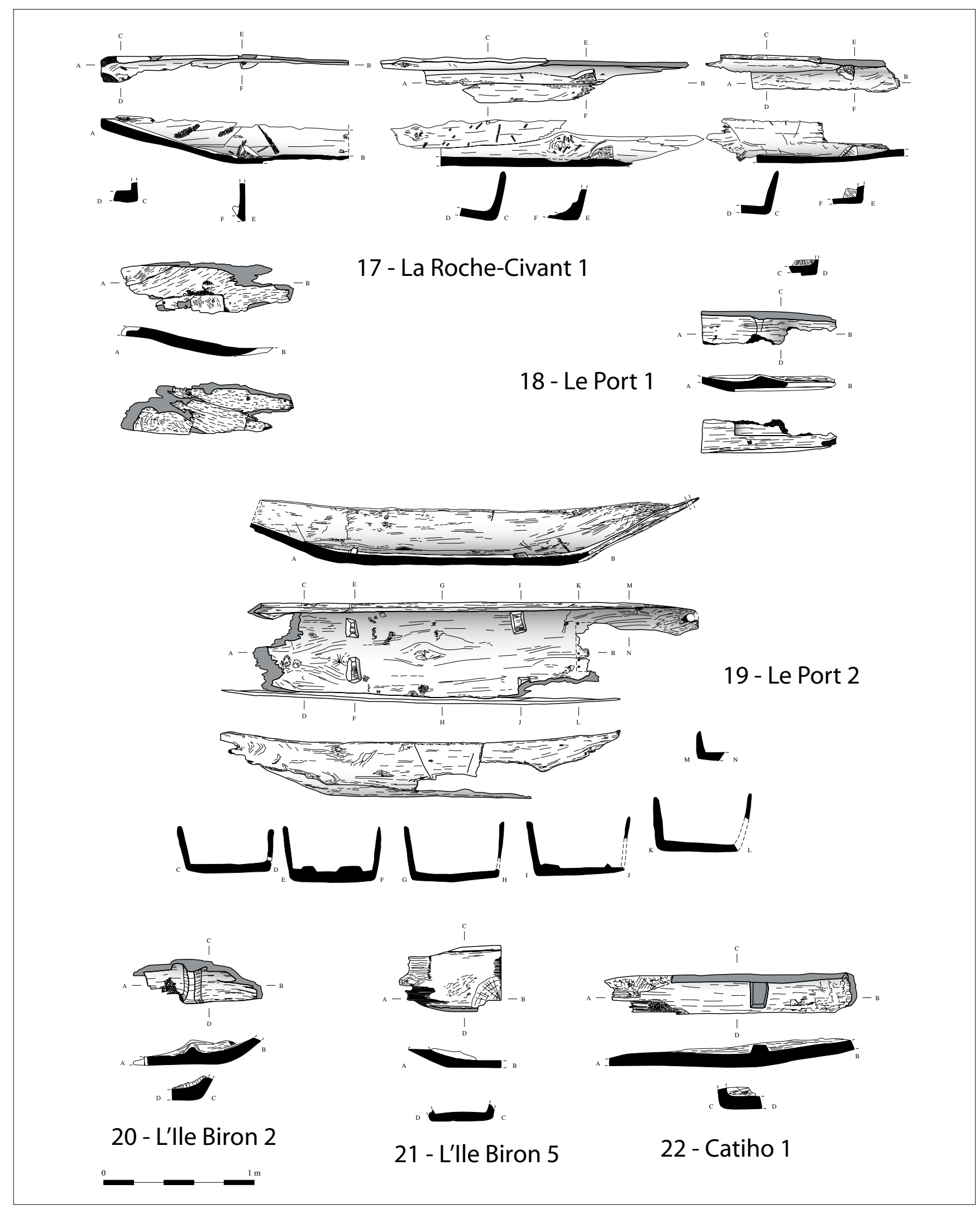

Figure 13 : Pirogues et fragments datés (17-19) ou non (20-22).

Figure 13: Dugouts and fragments, dated (17-19) and undated (20-22). 
[s] - Le Prieuré 2, Pont-Château : inv. AH26.003 (datation ${ }^{14} \mathrm{C}: 1000-1170 \mathrm{AD}$; non figuré).

Il s'agit du même type de pirogue que la précédente et il a par ailleurs été envisagé que ce fragment de 1,96 m de longueur pour $0,42 \mathrm{~m}$ de largeur puisse être la correspondance symétrique de Le Prieuré 1 [as], mais le bois utilisé ne provient pas du même chêne et l'épaisseur des flancs est trop différente. La levée est aussi plus prononcée. Cependant, on observe le même type de fond qui s'incurve vers l'extrémité et surtout la même disposition des jauges (ici six exemplaires dont deux tronqués), groupées par deux dans la partie médiane de l'embarcation. Ne s'agissant pas de la même pirogue, on peut avoir affaire au seul indice disponible concernant une production normée d'embarcations sur le Brivet. Mais deux monoxyles ne suffisent malheureusement pas à le prouver.

[t] - Le Port 1, Sainte-Anne sur Brivet : inv. Z01.012 (datation ${ }^{14} \mathrm{C}$ : 1014-1199 AD; fig. $13 \mathrm{n}^{\circ} 18$ ).

Il s'agit d'un fragment unique de fond et de départ de levée dont la longueur atteint $0,88 \mathrm{~m}$. La largeur et la hauteur initiales ne sont pas connues (largeur conservée : 0,21 m). Sur la face externe du fond, une empreinte de planchette est visible. Cette dernière a permis la conservation de traces d'outils (herminette). Une autre information intéressante est la trace de rayures anciennes qui témoignent des raclements $\mathrm{du}$ fond au moment des manœuvres d'accostage. L'angle du bouchain est de $95^{\circ}$. Enfin, sur la face interne, un léger ressaut indique le départ de la levée.

[u] - Le Port 2, Sainte-Anne sur Brivet : inv. Z01.020 (datation ${ }^{14} \mathrm{C}: 1190-1300 \mathrm{AD}$; fig. $13 \mathrm{n}^{\circ} 19$ ).

Quatre éléments composent cette embarcation longue en l'état de 3,16 m et large de 0,68 $\mathrm{m}$ : le fond, un des flancs et deux fragments du second flanc. Les bouchains ont des angles variant de $90^{\circ}$ à $100^{\circ}$. Les levées sont légèrement dissymétriques $\left(149^{\circ}\right.$ et $\left.157^{\circ}\right)$. Cette pirogue est archéologiquement complète, la seule de la collection avec La Soudenais 1 [m].

C'est la plus intéressante des pirogues découvertes dans le Brivet au point de vue de la typologie car elle associe à un mode d'architecture navale "primitif " - il s'agit encore d'un monoxyle - une réelle modernité qui la fait déjà ressembler à une barque. Les flancs sont fins, les cans sont biseautés, les levées apparaissent très profilées et symétriques. Les dimensions sont réduites mais l'embarcation s'apparente déjà à ce que seront bientôt les chalands ou les blins à l'époque Moderne. Elle est en outre équipée d'orifices d'ancrage ou d'amarrage, de cale-pieds taillés dans la masse du bois (fig. 14) et a été dotée d'une planchette de consolidation sous l'une de ses extrémités (quatre perforations et trois

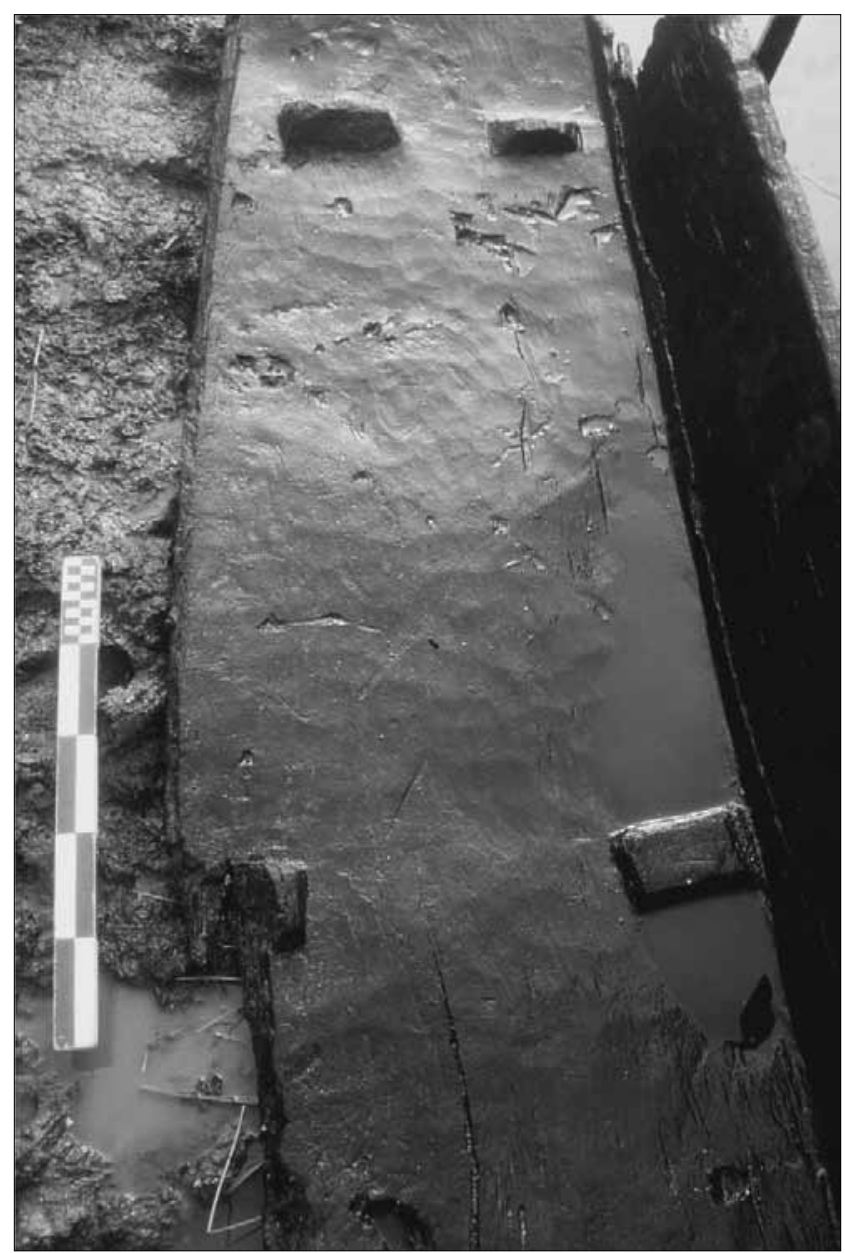

Figure 14 : Les quatre cale-pieds de la pirogue Le Port 2, réservés symétriquement sur le fond de l'embarcation (cl. C. Devals/AFAN, 1997).

Figure 14: The four feet wedges of Le Port 2 dugout, symetrically reserved when shaping the bottom of the craft.

gournables conservées : fig. 15 et infra fig. 21). Taillée dans un bois jeune avec de nombreux nœuds mais pas d'aubier, l'embarcation a conservé quelques traces d'outils, notamment sur son flanc interne bâbord.

\section{Catalogue des fragments de pirogues individualisées et non datées}

\section{Fragments recueillis sur la rive droite du Brivet (commune de Drefféac), d'amont en aval}

[v] - L'̂̂le Biron 2, Drefféac: inv. ZC11.004 (fig. 13 $\mathrm{n}^{\circ} 20$ ).

Il s'agit d'une levée dotée d'une nervure qui rappelle un peu L'Île Biron 1 [e], mais le fond est nettement moins épais. La forme du bec est indéterminée et les flancs sont absents. La longueur du fragment est de $0,85 \mathrm{~m}$ pour une largeur 


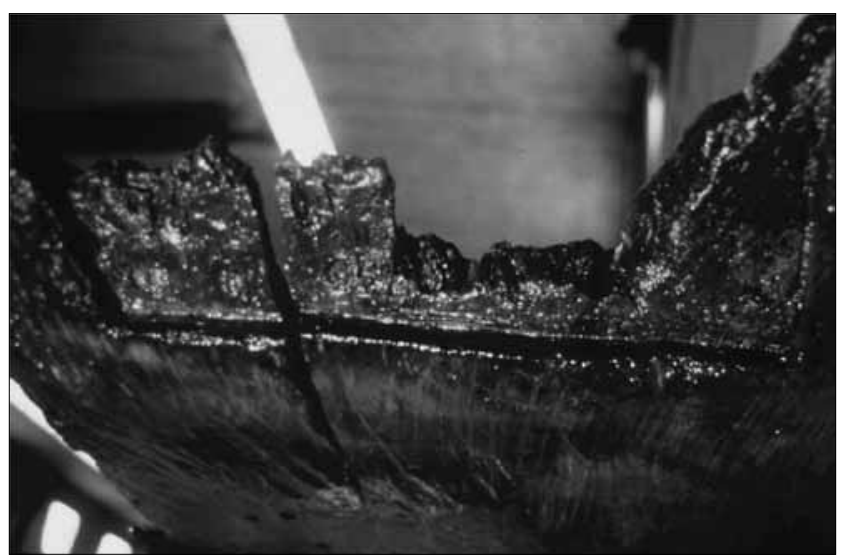

Figure 15 : Détail d'une levée externe de la pirogue Le Port 2 : contours de l'emplacement d'une planchette de réparation (cl. C. Devals/AFAN, 1997).

Figure 15: Detail of the external (lower) surface of one of the ends of Le Port 2 dugout: contour of a lost repair board.

(très incomplète) de 0,30 m. L'angle du bouchain est d'environ $120^{\circ}$.

[w] - L'̂lle Biron 3, Drefféac: inv. ZC11.005 (non figuré).

Cinq fragments sont susceptibles d'appartenir à cette pirogue, dont trois sont jointifs ou permettent la reconstitution partielle du fond dans sa largeur. Ce dernier est plat avec des bouchains dont l'angle par rapport au fond est de $135-140^{\circ}$. La longueur de l'ensemble reconstitué atteint $1,75 \mathrm{~m}$ pour une largeur estimée à $0,85 \mathrm{~m}$. Trois trous de chevilles sont répertoriés dans les deux principaux fragments.

[x] - L'̂lle Biron 4, Drefféac: inv. ZC11.006 (non figuré).

Il s'agit de deux fragments de départs d'extrémités opposées et d'un troisième qui est peut-être une partie de bouchain. La largeur du plus grand des fragments est de $0,28 \mathrm{~m}$ pour une longueur de $0,70 \mathrm{~m}$. Ces éléments, assurément d'une même pirogue, sont très détériorés. Vers les extrémités, l'angle du bouchain est de $140^{\circ}$.

[y] - L'Âle Biron 5, Drefféac: inv. ZC11.007 (fig. 13 $\left.\mathrm{n}^{\circ} 21\right)$.

Seul un fragment de fond et un départ de levée sont conservés. L'extrémité a disparu et la largeur n'est pas complète $(0,40 \mathrm{~m})$. Un nœud important est visible au niveau de la cassure médiane et interne du fond. La longueur du fragment est de $0,68 \mathrm{~m}$ et l'angle du bouchain est de $92^{\circ}$. [z] - L'Âle Biron 6, Drefféac: inv. ZC12.001 (non figuré).

C'est le bouchain (angle de $92^{\circ}$ ) qui constitue l'essentiel de ce qui reste de cette embarcation, longue de 1,46 m. Un départ de levée est encore visible sur $0,20 \mathrm{~m}$ de longueur et la largeur maximale du fond conservé est de $0,21 \mathrm{~m}$.

[aa] - L'Tle Biron 7, Drefféac: inv. ZC5b.003 (non figuré).

Ce fragment de flanc pourrait être positionné au niveau d'une extrémité. Le bois est très bien conservé et l'angle du bouchain est de $110-115^{\circ}$. La longueur de la pièce atteint à peine $0,38 \mathrm{~m}$ et le fond est totalement absent.

[ab] - Catiho 1, Drefféac: inv. ZH38b.028 (fig. 13 $\mathrm{n}^{\circ} 22$ ).

La levée et un départ de flanc sont préservés sur cet élément de 1,68 $\mathrm{m}$ de long pour 0,26 $\mathrm{m}$ de largeur maximale. Entre le fond et la base du flanc, un ressaut transversal est partiellement conservé (la partie supérieure en est arrachée). Même s'il est solidaire du flanc, il est possible qu'il ait pu s'agir d'un cale-pied.

[ac] - Catiho 2, Drefféac : inv. ZH38b.051 (non figuré). Ces deux fragments non jointifs d'une même pirogue présentent des nœuds et un bois fortement oxydé. Le premier atteint $2,11 \mathrm{~m}$ de longueur et le deuxième $2,63 \mathrm{~m}$; leurs largeurs sont respectivement de 0,20 et $0,22 \mathrm{~m}$. L'un d'eux possède une gournable.

[ad] - Catiho 3, Drefféac : inv. ZH38b.053 (non figuré). La longueur maximale de ces deux fragments jointifs est de 1,01 m pour une largeur de 0,14 m. L'angle du bouchain est de $93^{\circ}$ et la hauteur de la levée est de $0,13 \mathrm{~m}$. Un dessèchement important et des fissures caractérisent cet ensemble.

[ae] - Catiho 4, Drefféac : inv. ZH38b.060 (non figuré). À l'instar de la précédente embarcation, le bois est assez desséché. Ce fond atteint $2,35 \mathrm{~m}$ pour une largeur de $0,28 \mathrm{~m}$ et on devine encore un départ de flanc (angle du bouchain vif: $95^{\circ}$ ). Les fibres de bois sont obliques sur la face externe du flanc. Des traces de crocs sont visibles sur la face externe.

[af] - La Soudenais 4, Drefféac : inv. ZH39d.075 (fig. 16 $\left.\mathrm{n}^{\circ} 23\right)$.

Ces deux fragments jointifs correspondent à un fond arrondi, large de $0,60 \mathrm{~m}$ pour $1,33 \mathrm{~m}$ de longueur. Si la face interne montre un bois dont les lignes sont bien visibles ainsi que de nombreuses traces de vers, la face externe (exception- 


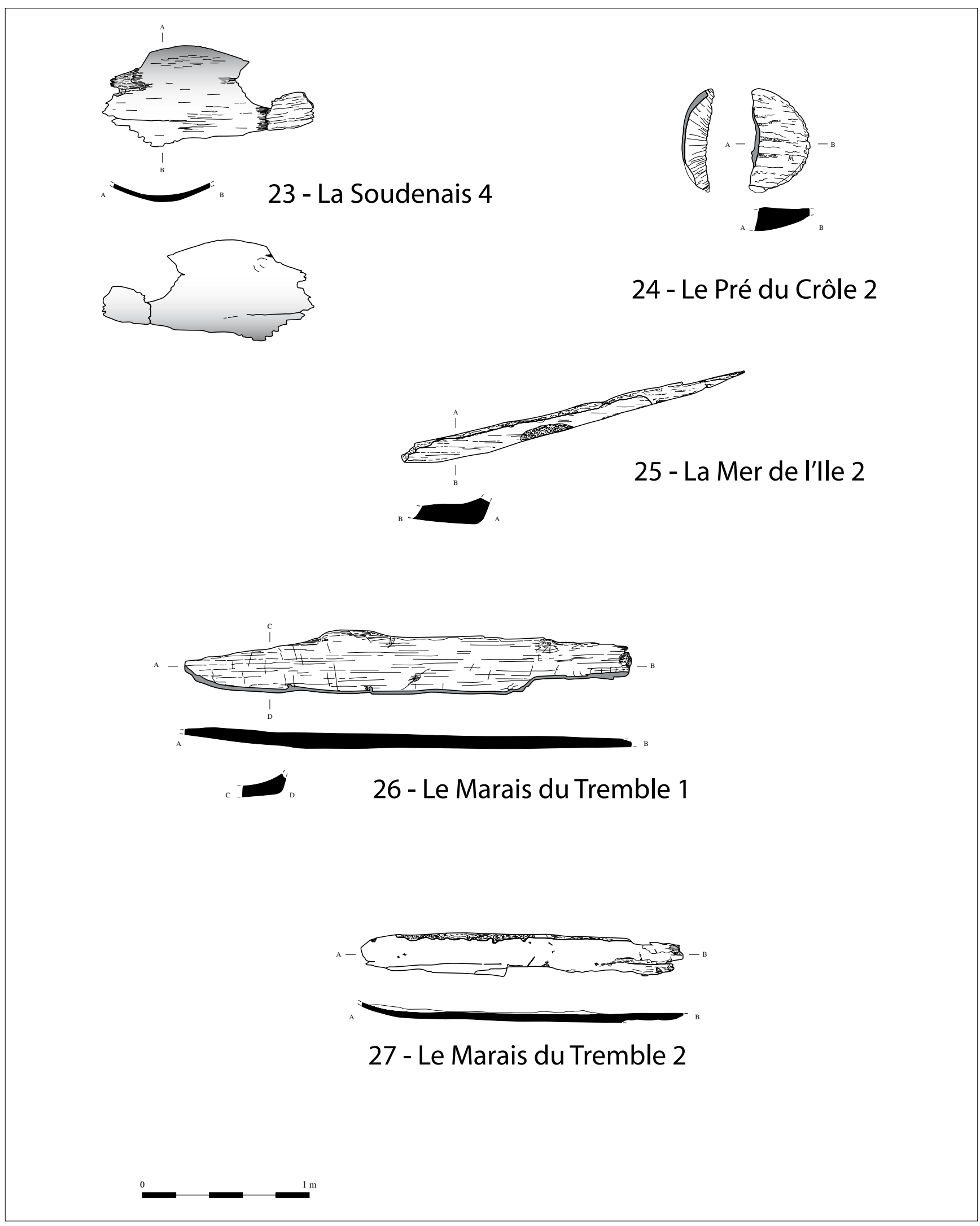

Figure 16 : Fragments divers non datés.

Figure 16: Miscellaneous fragments undated. 
nellement figurée) est parfaitement lisse et conserve même trois empreintes d'une herminette dont l'extrémité du fer était arrondie.

[ag] - La Soudenais 5, Drefféac : inv. ZH39d.080 (non figuré).

Ce fragment très desséché est un fond avec un départ de levée. Sa longueur est de 0,84 $\mathrm{m}$ pour 0,18 $\mathrm{m}$ de large.

[ah] - La Soudenais 7, Drefféac : inv. ZH39d.090 (non figuré).

Ces deux fragments de fond sont jointifs au niveau de la ligne médiane. Un départ de levée est visible et le bouchain conservé présente un angle de $110^{\circ}$. La longueur de l'ensemble est de $1,42 \mathrm{~m}$ pour $0,38 \mathrm{~m}$ de large. Un des deux fragments présente trois minuscules perforations voisines mais pas alignées (diamètres de 1,6 à 1,8 mm).

[ai] - Le Pré du Crôle 2, Drefféac : inv. ZI42.006 (fig. 16 $\left.\mathrm{n}^{\circ} 24\right)$.

Cette extrémité possède un bec semi-circulaire, long de $0,35 \mathrm{~m}$ pour $0,19 \mathrm{~m}$ de large. La face externe (non figurée) conserve peut-être des traces d'outils. Il s'agit d'un gradin et de sa contremarche (angle de $103^{\circ}$ ). Le fond de la pirogue est encore discernable à la base de la contremarche.

\section{Fragments recueillis sur la rive gauche du Brivet (commune de Sainte-Anne sur Brivet), d'amont en aval}

[aj] - La Mer de l'île 1, Sainte-Anne sur Brivet : inv. ZS1.001 (non figuré).

Seul un fragment de fond et un bouchain incomplet en sont conservés. Très abîmée, cette pièce atteint $1,56 \mathrm{~m}$ de long pour 0,30 $\mathrm{m}$ de large. L'angle du bouchain est de 110 $115^{\circ}$.

[ak] - La Mer de l'île 2, Sainte-Anne sur Brivet: inv. ZS1.014 (fig. $16 \mathrm{n}^{\circ} 25$ ).

Du fait de l'orientation des fibres du bois visibles sur la face externe du bouchain (angle de $105^{\circ}$ ) et de l'angle présent sur une des extrémités, il est probable que ce fragment long de $1,85 \mathrm{~m}$ soit une levée dont l'élancement au bec serait de 0,40 à $0,50 \mathrm{~m}$ de hauteur. Cette embarcation devait donc être particulièrement longue. Le départ du fond est conservé.

[al] - Tinfois 1, Sainte-Anne sur Brivet : inv. ZO32.007 (non figuré).

Trois fragments dont deux sont jointifs composent cet ensemble très mal conservé. La longueur du fragment principal n'est que de $0,43 \mathrm{~m}$ pour une largeur de $0,27 \mathrm{~m}$. Le fond est épais, le bouchain arrondi et le flanc va en s'amincissant.

[am] - Le Marais du Tremble 1, Sainte-Anne sur Brivet: inv. $\mathrm{ZO} 21.016$ (fig. $16 \mathrm{n}^{\circ}$ 26).

Seul un grand élément de fond de cette embarcation nous est parvenu, long de 2,68 $\mathrm{m}$ et large de $0,37 \mathrm{~m}$, avec une amorce de bouchain et un départ d'extrémité. La surface interne, sur laquelle on observe de nombreuses fentes, est très desséchée ainsi qu'un nœud et un trou non perforant (de coléoptère xylophage ?).

[an] - Le Marais du Tremble 2, Sainte-Anne sur Brivet: inv. ZO21.017 (fig. $16 \mathrm{n}^{\circ}$ 27).

Comme pour la pirogue précédente, il s'agit d'un long fragment de fond (1,92 $\mathrm{m}$ de long pour 0,26 $\mathrm{m}$ de large), avec une amorce de bouchain, dont l'angle vif est de $93^{\circ}$, et un départ de levée. Quelques traces de coups de fouëne sont présentes sur la face interne, alors que l'extérieur est intact. L'épaisseur du can arraché du flanc est de $2 \mathrm{~cm}$.

[ao] - Le Port 3, Sainte-Anne sur Brivet : inv. Z01.089 (fig. $17 \mathrm{n}^{\circ} 28$ ).

Ce fragment provient d'une pirogue qui semble morphologiquement voisine de celle dite Le Port 2 [u]. Toutefois, le flanc et le can sont ici moins hauts et le bois n'est pas de même texture. Il s'agit d'un fragment de fond avec un départ de levée comportant un orifice d'ancrage ou d'amarrage très détérioré ( $3 \mathrm{~cm}$ de diamètre). Sa longueur est de $1,46 \mathrm{~m}$ pour une largeur sans doute très tronquée de $0,18 \mathrm{~m}$. L'angle du bouchain au niveau de la levée est de $110^{\circ}$. Deux nœuds, l'un sur l'extrémité de la levée, l'autre sur l'avant du flanc, sont visibles. Enfin, deux gournables sont présentes sur l'extrémité mais leur fonction n'est pas connue : elles n'ont apparemment pas servi à la fixation d'une planchette de réparation ou de consolidation.

[ap] - La Gagnerie d'Abar 1, Sainte-Anne sur Brivet : inv. ZK1.003 (fig. $17 \mathrm{n}^{\circ} 29$ ).

Quatorze fragments non jointifs composent cet ensemble, dont un seul est attesté comme partie du fond et ses départs de flancs (cf. dessin). La longueur de ce fragment est de $0,78 \mathrm{~m}$ pour une largeur de $0,66 \mathrm{~m}$ et il est doté d'une nervure ou d'un renfort transversal très érodé. L'angle du bouchain arrondi est de $140^{\circ}$.

[aq] - La Gagnerie d'Abar 2, Sainte-Anne sur Brivet : inv. ZK1.004 (non figuré).

Le fragment le plus imposant de cet ensemble de dix pièces est un flanc de 1,24 $\mathrm{m}$ de longueur avec son bouchain (angle de $112^{\circ}$ ) et de très rares vestiges du fond. On observe 


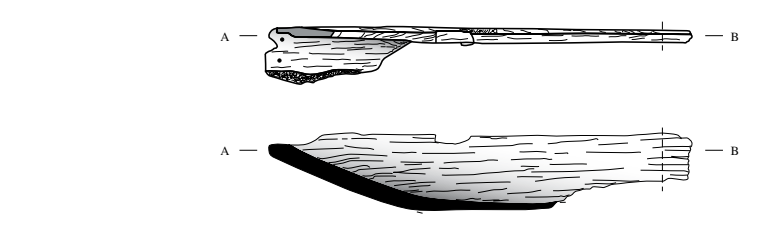

28 - Le Port 3
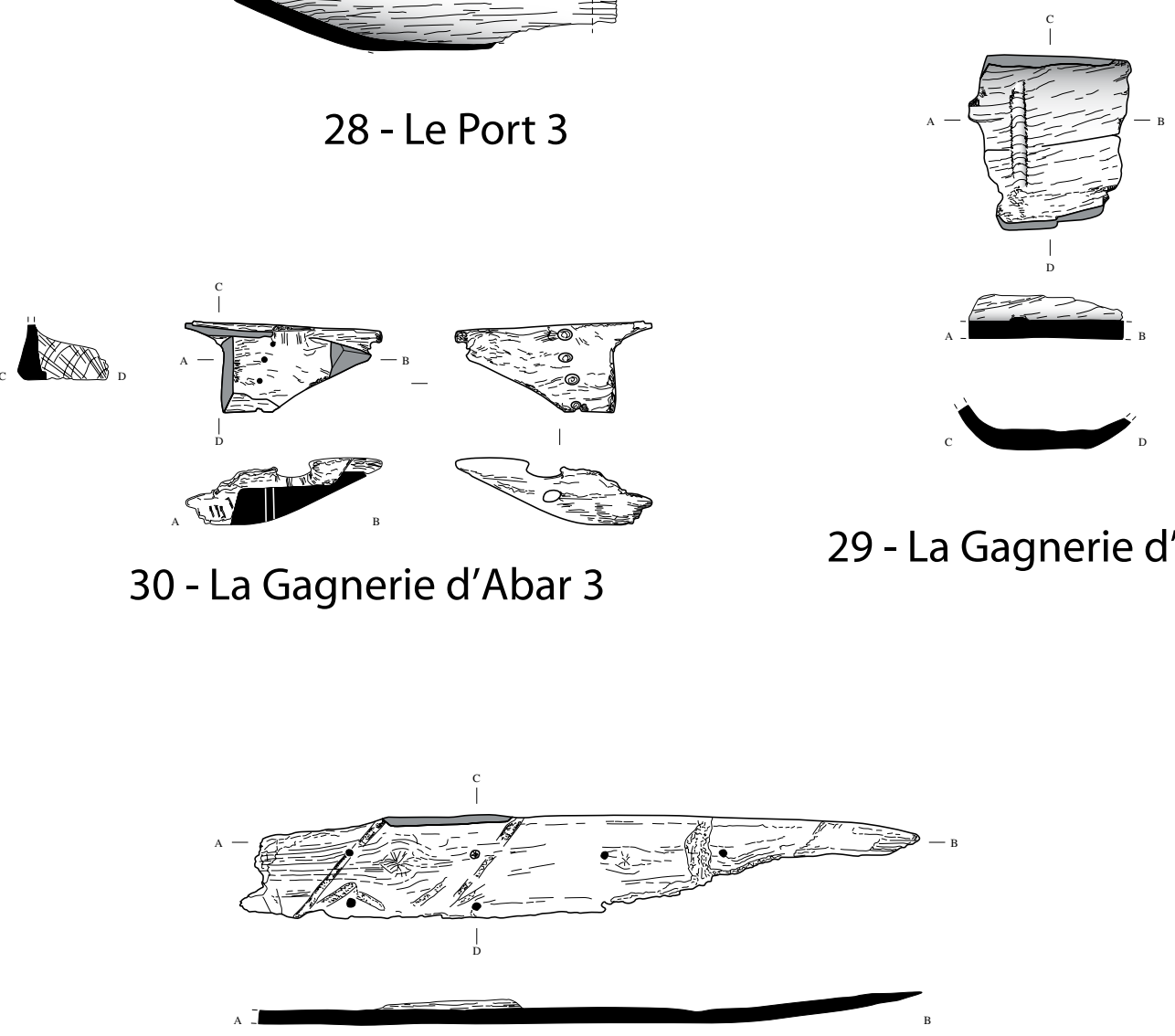

29 - La Gagnerie d'Abar 1

- 31 - Le Prieuré 1

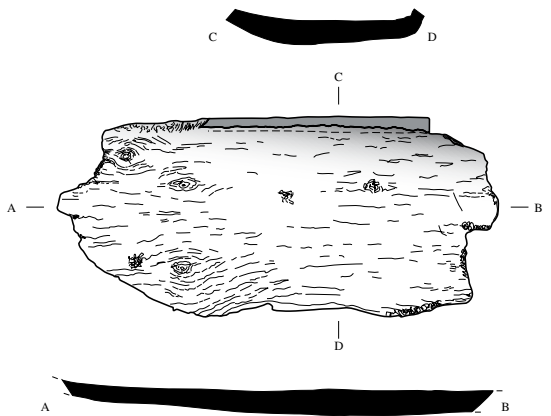

32 - Coët Roz 1
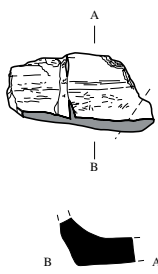

33 - La Roche-Civant 2 
aussi un départ plausible de levée sur le plus gros des fragments.

[ar] - La Gagnerie d'Abar 3, Sainte-Anne sur Brivet : inv. ZK1.007 (fig. $17 \mathrm{n}^{\circ}$ 30).

Cette extrémité à bec large et gradin ou seuil est originale; on observe en effet sur un des flancs un orifice d'amarrage ou d'ancrage mais aussi quatre stries témoignant d'un passage répété de cordages. Sur la face externe, quatre trous non perforants et grossièrement alignés demeurent énigmatiques quant à leur fonction. Ce fragment est long de $0,73 \mathrm{~m}$ et large au mieux de $0,33 \mathrm{~m}$ pour une hauteur de $0,19 \mathrm{~m}$.

\section{Fragments recueillis sur les deux rives du Brivet} (commune de Pont-Château), d'amont en aval

[as] - Le Prieuré 1, Pont-Château : inv. AH26.002 (fig. 17 $\left.\mathrm{n}^{\circ} 31\right)$.

Ce grand fond de $2,56 \mathrm{~m}$ de long pour $0,38 \mathrm{~m}$ de large est desséché sur sa face interne mais bien préservé sur sa face externe. Un départ de levée y est observable mais les flancs ont disparu (angle du bouchain : 95-100 ${ }^{\circ}$ ). Sept jauges sont visibles, groupées par deux tous les 0,15 à $0,17 \mathrm{~m}$ avec des diamètres de 2,8 à $2,9 \mathrm{~cm}$. Une seule a conservé une gournable.

[at] - Le Prieuré 3, Pont-Château : inv. AH26.004 (non figuré).

Ce fragment de fond, très desséché (crevasses de plusieurs centimètres de profondeur), est encore long de $2,31 \mathrm{~m}$ pour $0,49 \mathrm{~m}$ de large. Une levée légère $\left(4^{\circ}\right)$ est observable et l'aubier est conservé sur un des côtés du fond. Trois gournables, dont au moins deux sont pointues, sont en place et la plus grande d'entre elles présente des traces de calfatage (mousse).

[au] - Coët Roz 1, Pont-Château : inv. ZP107.002 (fig. 17 $\left.\mathrm{n}^{\circ} 32\right)$.

Il s'agit encore d'un fragment de fond et de levée, long de $1,52 \mathrm{~m}$ pour $0,67 \mathrm{~m}$ de large, ce qui en fait une des pirogues les plus " spacieuses » du Brivet. Le bois est riche en nœuds et l'état général du fragment est médiocre.

[av] - Coët Roz 2, Pont-Château : inv. ZP18.003 (non figuré).

Cet ensemble est l'un des plus abîmés de la série du fait d'un dessèchement très important. Quatre fragments n'ont pu être étudiés du fait de leur trop mauvais état de conservation. La longueur du seul fragment étudiable n'est que de $0,51 \mathrm{~m}$ pour $0,34 \mathrm{~m}$ de large. On perçoit cependant bien la forme du gradin qui possède en outre deux perforations sur un de ses côtés. L'angle du gradin est de 105 à $110^{\circ}$ et la hauteur de la contremarche de $0,10 \mathrm{~m}$. [aw] - L'Angle Hermine 1, Pont-Château: inv. ZW138d.002 (non figuré).

Cette pirogue est représentée par un fragment de fond avec un départ de levée et un flanc embryonnaire, l'ensemble atteignant 1,91 m de longueur pour une largeur de 0,21 m. Les deux faces sont très desséchées et seul le profil longitudinal a pu être relevé correctement. L'angle du bouchain est de 95 à $100^{\circ}$.

[ax] - La Roche-Civant 2, Pont-Château : inv. YO103.015 (fig. $17 \mathrm{n}^{\circ} 33$ ).

Cette petite pièce est exceptionnelle à deux titres.

- En premier lieu, ce fragment de fond et de flanc (longueur maximale $0,49 \mathrm{~m}$, largeur $0,25 \mathrm{~m}$, angle du bouchain $112^{\circ}$ ) est doté d'un tableau arrière, comme La CrôleVillangeais 1 [a] (cf. supra, fig. 4 et 5). Mais alors que ce dernier est une double réserve, cet exemplaire montre une simple rainure creusée transversalement dans le fond de la pirogue. Le principe est cependant le même : accueillir une planchette de fermeture (qui est ici absente).

- De plus, il s'agit de la seule pirogue du Brivet qui ne soit pas en chêne mais en aulne (Alnus glutinosa).

Fragments recueillis sur les rives du Brivet (commune de Besné), d'amont en aval

[ay] - Le Grand Marais 1, Besné : inv. ZV12.008 (non figuré).

Ce fragment de fond est très desséché. Le bouchain est visible et son angle arrondi est de $100^{\circ}$. La longueur est de $1,90 \mathrm{~m}$ pour $0,34 \mathrm{~m}$ de largeur.

[az] - Le Grand Marais 2, Besné : inv. ZV12.012 (non figuré).

Le bois n'est pas le même que celui utilisé pour la construction de la pirogue précédente, ce qui permet de différencier cet exemplaire du précédent. Très desséché mais tout de même long de 1,69 m pour 0,42 $\mathrm{m}$ de large, ce fragment de fond possède aussi un bouchain à angle de $100^{\circ}$.

\section{Autres éléments}

\section{Fragments de pirogues indifférenciées (tableau 2)}

Vingt et un éléments importants, parfois riches en informations d'ordre technologique, n'ont pas été individualisés comme pirogues lors de la phase d'étude. À l'époque, en effet, aucun des quatre critères nécessaires à leur différenciation n'a pu être satisfait (géographie, typologie, matériau, datation). Depuis, trois éléments dont deux appartiennent finalement à des embarcations ont été datés par dendrochronologie, ce qui a permis de compléter le corpus des pirogues 


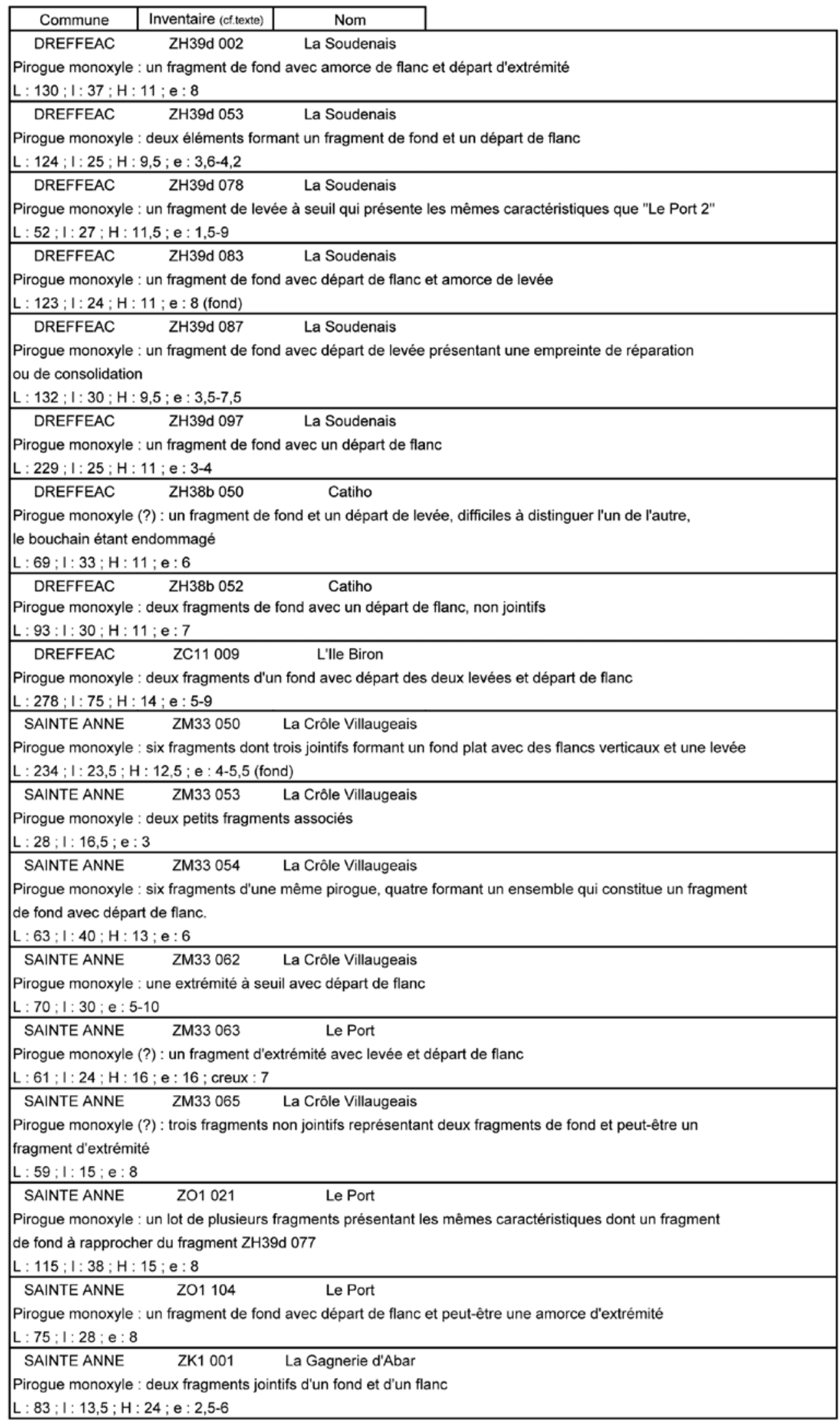

Tableau 2 : Pirogues non individualisées (avec dimensions en centimètres pour les fragments principaux).

Table 2: Elements of non individualized dugouts (with dimensions in $\mathrm{cm}$ for the main fragments). 
individualisées : Le Port 8 [o] et La Crôle-Villangeais 3 [q], étudiées ci-dessus). Les 18 éléments restants (non figurés) attendent à leur tour une datation.

\section{Objets divers liés à la petite batellerie (tableaux 3 et 4)}

Plusieurs pièces isolées ayant appartenu à des pirogues (planchettes de réparation / consolidation et varangues) ou ayant trait à la batellerie (rames, pagaies ou gaffes) ont également été recueillies. Dix planchettes ont été répertoriées (fig. 18), toutes en chêne et pour sept d'entre elles découvertes dans les secteurs limitrophes du Port - La Soudenais - La
Crôle-Villaugeais (voir ci-dessous). Enfin, une petite pièce demeure une énigme (fig. $18 \mathrm{n}^{\circ}$ 36). D’après Eric Rieth, il pourrait s'agir d'un élément de réparation d'un flanc d'embarcation.

Les varangues, qui sont des pièces de bois rapportées et non des réserves, sont au nombre probable de quatre car deux d'entre elles ne sont conservées que sur leur partie longue (fond de l'embarcation) et ne peuvent donc être formellement identifiées (fig. $19 \mathrm{n}^{\circ} 41,43$ ).

Les rames ou pagaies sont au nombre de six dont quatre sont figurées ici (fig. $19 \mathrm{n}^{\circ}$ 45-48). Deux pales sont assurées, toutes deux en chêne; l'une, découverte au lieu-dit Le Port,
Tableau 3: Planchettes, varangues et pièces indéterminées.

Table 3: Repair boards, ribs and undetermined pieces.

\begin{tabular}{|c|c|c|}
\hline $\mathrm{N}^{\circ}$ & Commune & Nom \\
\hline \multirow[t]{2}{*}{34} & $\begin{array}{l}\text { DREFFEAC ZH39d } 047 \\
\text { Un fragment de planchette de répar } \\
\mathrm{L}: 49,5 ; \mathrm{I}: 13 ; \mathrm{e}: 3\end{array}$ & $\begin{array}{l}\text { La Soudenais } \\
\text { tion ou de consolidation avec quatre perforations }\end{array}$ \\
\hline & $\begin{array}{l}\text { DREFFEAC } \quad \mathrm{ZH} 39 \mathrm{~d} 074 \\
\text { Un petit fragment légèrement courb } \\
\mathrm{L}: 16,5 ; \mathrm{l}: 6 ; \text { e }: 1,5 \\
\end{array}$ & $\begin{array}{l}\text { La Soudenais } \\
\text { d'une petite planchette perforée }\end{array}$ \\
\hline 35 & $\begin{array}{l}\text { DREFFEAC } \quad \text { ZH39d } 084 \\
\text { Trois planchettes de réparation ou } \\
\mathrm{PI} 1-\mathrm{L}: 58 ; \mathrm{I}: 11,8 ; \text { e }: 0,5-3-\mathrm{PI}\end{array}$ & $\begin{array}{l}\text { La Soudenais } \\
\text { consolidation avec orifices de fixation } \\
-\mathrm{L}: 54 ; \mathrm{I}: 10,8 ; \mathrm{e}: 1-1,7-\mathrm{pl} 3-\mathrm{L}: 58 ; \mathrm{I}: 11 ; \mathrm{e}: 1,2-2,5\end{array}$ \\
\hline 36 & $\begin{array}{l}\text { DREFFEAC } \quad \text { ZH39d } 094 \\
\text { Une planchette (?) de réparation de } \\
\mathrm{L}: 26,5 ; 1: 6,5 ; \text { e }: 5,5\end{array}$ & $\begin{array}{l}\text { La Soudenais } \\
\text { anc de pirogue }\end{array}$ \\
\hline 37 & $\begin{array}{l}\text { DREFFEAC } \quad \text { ZH39d } 096 \\
\text { Quatre fragments d'une planchette } \\
\mathrm{L}: 44,5 ; \mathrm{I}: 17,5 ; \mathrm{e}: 1,3-3,9 \\
\end{array}$ & $\begin{array}{l}\text { La Soudenais } \\
\text { réparation ou de consolidation }\end{array}$ \\
\hline 1 & $\begin{array}{l}\text { SAINTE ANNE ZM33 } 011 \\
\text { Deux fragments formant une planch } \\
L: 14 ; 1: 12 ; \text { e : } 0,7-1,7 \\
\end{array}$ & $\begin{array}{l}\text { La Crôle Villaugeais } \\
\text { tte de réparation ou de consolidation avec deux trous de fixation }\end{array}$ \\
\hline 1 & $\begin{array}{l}\text { SAINTE ANNE ZM33 } 056 \\
\text { Un fragment de planchette de répar } \\
\mathrm{L}: 8 ; 1: 8,8 ; \mathrm{e}: 2\end{array}$ & $\begin{array}{l}\text { La Crôle Villaugeais } \\
\text { tion perforée présentant aujourd'hui la forme d'un triangle }\end{array}$ \\
\hline 38 & $\begin{array}{l}\text { SAINTE ANNE ZM33 } 064 \\
\text { Une planchette de réparation (?) tr } \\
\mathrm{L}: 51: 1: 12 ; \mathrm{e}: 3\end{array}$ & $\begin{array}{l}\text { La Crôle Villaugeais } \\
\text { dessèchée avec emplacement de sept gournables }\end{array}$ \\
\hline 39 & $\begin{array}{l}\text { SAINTE ANNE ZO1 } 062 \\
\text { Un fragment de planchette de répar } \\
\mathrm{L}: 27 ; 1: 18 ; \mathrm{e}: 3,5\end{array}$ & $\begin{array}{l}\text { Le Port } \\
\text { tion (?) dotée de deux perforations }\end{array}$ \\
\hline 40 & $\begin{array}{l}\text { SAINTE ANNE ZK1 } 010 \\
\text { Neuf fragments (dont deux disjoints } \\
\text { Un fragment disjoint comporte un tr } \\
L: 34 ; 1: 12,5 ; \text { e : } 1-5\end{array}$ & $\begin{array}{l}\text { La Gagnerie d'Abar } \\
\text { d'une planchette quadrangulaire avec un bord biseauté et un bord droit. } \\
\text { de cheville de } 2,1 \mathrm{~cm} \text { de diamètre }\end{array}$ \\
\hline 41 & $\begin{array}{l}\text { DREFFEAC ZC5b } 003 \\
\text { Une varangue et un fragment d'une } \\
L: 22,5 ; 1: 6,2 ; \mathrm{e}: 4\end{array}$ & $\begin{array}{l}\text { L'lle Biron } \\
\text { atre varangue associés à la pirogue L'lle Biron } 7\end{array}$ \\
\hline 42 & $\begin{array}{l}\text { SAINTE ANNE } \quad \text { ZM33 } 051 \\
\text { Une varangue très peu large avec } t \\
\mathrm{~L}: 79 ; 1: 5 ; \mathrm{H}: 37 ; \mathrm{e}: 8 \\
\end{array}$ & $\begin{array}{l}\text { La Crôle Villaugeais } \\
\text { is gournables }\end{array}$ \\
\hline 43 & $\begin{array}{l}\text { SAINTE ANNE ZO1 } 028 \\
\text { Un fragment de varangue percée d } \\
\mathrm{L}: 51 ; 1: 11 ; \mathrm{e}: 8 \\
\end{array}$ & $\begin{array}{l}\text { Le Port } \\
\text { inq trous de chevilles et un trou plus étroit oxydé (clou ?) }\end{array}$ \\
\hline 44 & $\begin{array}{l}\text { PONT CHÂTEAU ZW138d } 003 \\
\text { Un fragment de varangue } \\
\mathrm{L}: 67 ; \mathrm{I}: 10 ; \mathrm{H}: 23,5 ; \mathrm{e}: 8\end{array}$ & L'Angle Hermine \\
\hline
\end{tabular}

S. Leray, Inrap 


\begin{tabular}{|c|c|c|c|}
\hline $\mathrm{N}^{\circ}$ & Commune & Inventaire & Nom \\
\hline 45 & \begin{tabular}{|c|}
\multicolumn{1}{c}{ DREFFEAC } \\
Fragments de pale \\
$\mathrm{L}: 106,5 ; 1: 14$ \\
\end{tabular} & $\begin{array}{l}\mathrm{ZH} 39 \mathrm{~d} 046 \\
\text { manche de }\end{array}$ & aie \\
\hline 1 & $\begin{array}{l}\text { SAINTE ANNE } \\
\text { Un petit fragment de } \\
L: 12,3 ; 1: 4 \\
\end{array}$ & $\begin{array}{c}\text { ZM33 } 059 \\
\text { manche de } p\end{array}$ & $\begin{array}{l}\text { La Crôle Villaugeais } \\
\text { aie ou de manche d'outil (section : } 4,2 \times 2,4 \mathrm{~cm} \text { ) }\end{array}$ \\
\hline 46 & \begin{tabular}{|l} 
SAINTE ANNE \\
Deux fragments de \\
$L: 31,5 ; 1: 6,5$ \\
\end{tabular} & $\begin{array}{l}\text { ZM33 } 061 \\
\text { lanche de pa }\end{array}$ & $\begin{array}{l}\text { La Crôle Villaugeais } \\
\text { e dont l'extrémité comportant le pommeau (section : } 6 \text { c 2,2 cm) }\end{array}$ \\
\hline 47 & $\begin{array}{l}\text { SAINTE ANNE } \\
\text { Une extrémité de pe } \\
L: 37: 1: 4 ; \text { e }: 2,5\end{array}$ & $\begin{array}{l}\text { ZO1 } 033 \\
\text { aie avec le } p\end{array}$ & meau \\
\hline 1 & $\begin{array}{l}\text { SAINTE ANNE } \\
\text { Un objet évoquant } L \\
L: 39 ; 1: 21 ; \mathrm{e}: 3 \\
\end{array}$ & $\begin{array}{l}\mathrm{ZO1} 205 \\
\text { le rame avec }\end{array}$ & $\begin{array}{c}\text { Le Port } \\
\text { q occlusions dans sa partie centrale }\end{array}$ \\
\hline 1 & $\begin{array}{l}\text { PONT CHÂTEAU } \\
\text { Un fragment de "ga } \\
\text { L : } 94\end{array}$ & $\begin{array}{l}\text { YO103016 } \\
\text { e" (?) }\end{array}$ & La Roche Civant \\
\hline 48 & $\begin{array}{l}\text { Non localisé } \\
\text { Un fragment de pale } \\
\text { L: } 50 ; 1: 24 ; \mathrm{e}: 3\end{array}$ & de pagaie & \\
\hline
\end{tabular}

Tableau 4 : Pagaies et rames. Tableau 4: Paddles and oars. était assemblée par chevillage à son manche disparu, tout comme la deuxième dont on ignore le lieu précis de découverte $\left(n^{\circ} 48\right)$. Une pagaie monoxyle presque complète est taillée dans un bois tendre (bouleau? - $\mathrm{n}^{\circ} 45$ ). Deux fragments de manches de pagaies à pommeau complètent cette série; ils sont identifiés comme tels par la section du bois et l'élargissement du manche vers l'extrémité brisée $\left(\mathrm{n}^{\circ} 46\right.$ et 47). N'est pas figuré un troisième manche très fragmentaire, en fait une probable pointe de gaffe effilée dont l'extrémité est brisée.

Des pierres de mouillage ou ancres, triangulaires, en schiste ou en granite, ont aussi été découvertes. Elles sont au nombre de deux authentifiées et d'une troisième plus incertaine. Ces pierres sont assez fréquentes en Bretagne et sont généralement datées de la Protohistoire lato sensu (Langouët et al., 1999, p. 5-24).

\section{LE FAÇONNAGE}

\section{L'arbre et sa coupe}

On sait que les essences utilisées sont très différentes selon les régions d'Europe et dépendent ordinairement des opportunités locales. Ainsi les pirogues confectionnées à partir de tilleul, de pin, d'aulne et même de peuplier se rencontrent un peu partout et pour toutes les époques. Les embarcations du Brivet sont toutes confectionnées à partir de troncs de chêne évidés à l'exception de La Roche-Civant 2 [ax] qui est en aulne (Alnus glutinosa). Ce quasi monopole du chêne
(Quercus sp.) s'explique par le couvert forestier régional où cet arbre prédomine largement depuis le Néolithique.

Abondant, solide, résistant, moins sensible aux variations climatiques que nombre d'autres espèces, souvent de grande taille et de large circonférence, le chêne est le bois presque idéal même s'il est parfois difficile à travailler. Malheureusement aucune indication ne nous est apparue quant au mode d'abattage puis de séchage du bois. Cependant, des exemples ethnographiques montrent souvent une utilisation de bois vert fraîchement coupé, ce qui a pu être le cas ici.

La qualité des bois est en revanche très variable, certaines pirogues ayant été réalisées avec des troncs très noueux et quelquefois fendus dès l'origine. On constate à ce niveau que les périodes concernées jouent peu et que la qualité du matériau n'influe pas sur l'importance des travaux de finition.

Les arbres utilisés sont divers, de l'exemplaire jeune aux cernes larges (Le Port $2[\mathrm{u}])$ à l'arbre vieillissant (La CrôleVillaugeais $2[\mathrm{c}])$. On reconnaît aussi la présence de nombreux noeuds sur certaines embarcations, en particulier $L e$ Port $2[\mathrm{u}]$ mais aussi L'̂́le Biron 4 et $5[\mathrm{x}]$ et [y], Catiho 2, 3 et $4[\mathrm{ac}]$, [ad] et [ae], La Soudenais 1,2 et $3[\mathrm{~m}]$, [k] et [h], Le Prieuré 1 et 3 [as] et [at], Coët Roz 1 [au], L'Angle Hermine 2 [p], La Crôle-Villangeais 2 [c], Le Port 3 et 6 [ao] et [j], Marais du Tremble 1 [am] et Tinfois 2 [d]. De grandes fentes, peut-être d'origine, sont reconnaissables, en particulier sur La Soudenais $1[\mathrm{~m}]$ mais aussi sur certains exemplaires à planchettes, comme par exemple La Soudenais 3 [h]. 


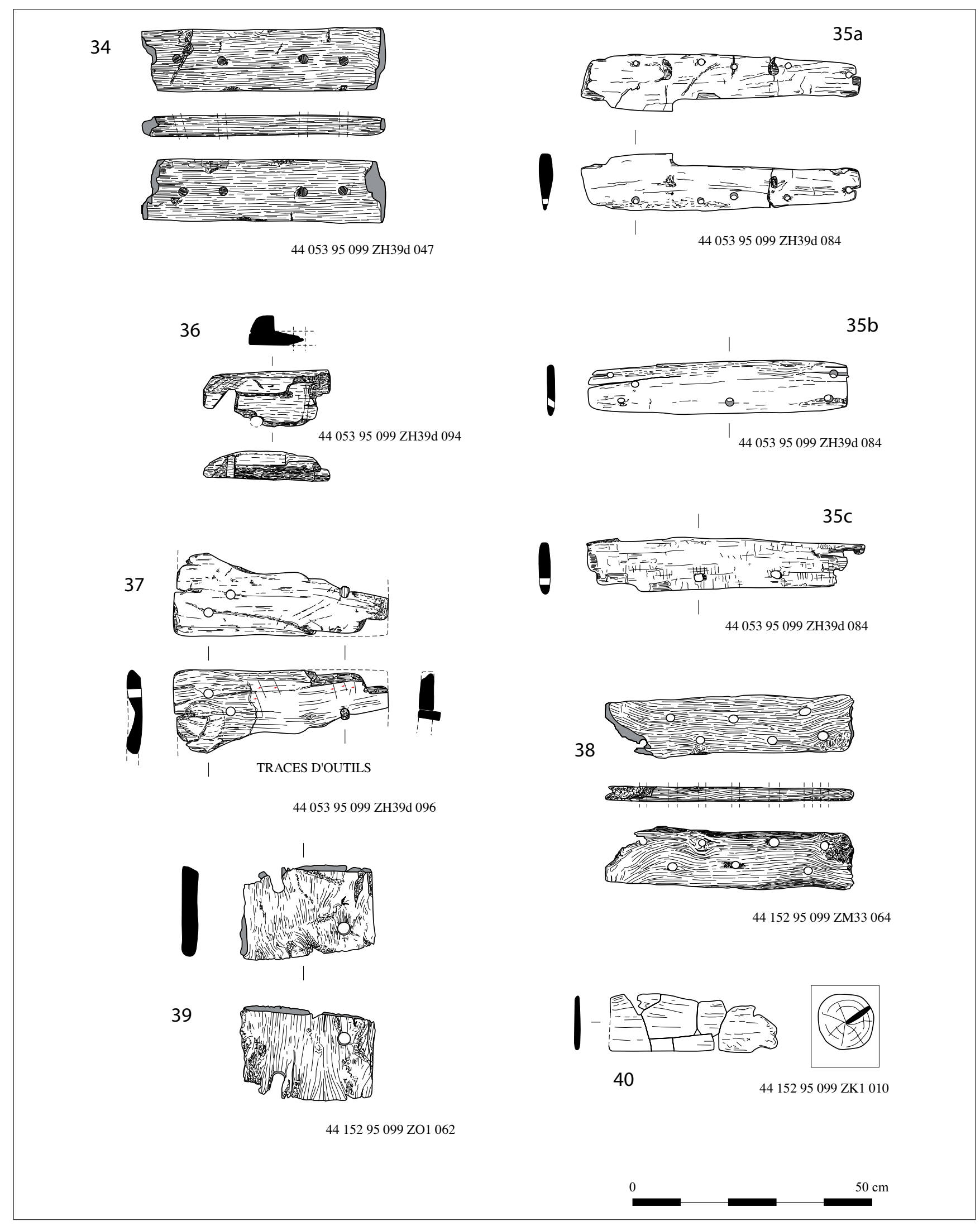

Figure 18 : Planchettes de réparation et divers.

Figure 18: Repair boards and miscellaneaous. 


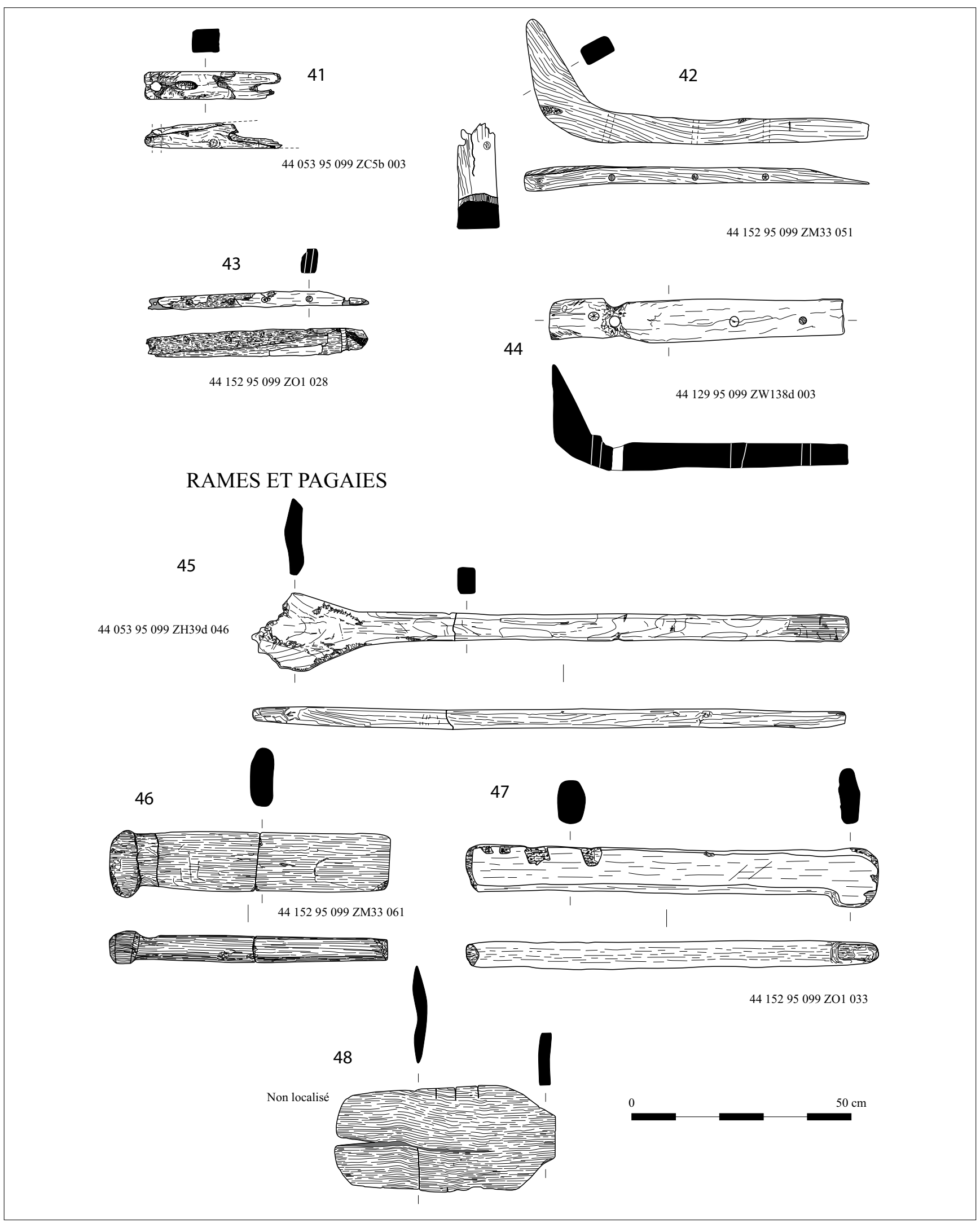

Figure 19 : Varangues, rames et pagaies.

Figure 19: Ribs, oars and paddles. 


\section{L'évidement}

\section{Traces d'outils}

C'est un des apports majeurs de la série du Brivet: les traces d'outils sont relativement fréquentes et leur bonne conservation est due à trois raisons principales. La première, purement conjoncturelle, est liée au fait que l'étude a été effectuée peu de temps après leur découverte et alors que les embarcations étaient restées constamment immergées après leur récupération sur les bords de la rivière. Toutefois, plusieurs fragments avaient été antérieurement desséchés, ôtant toute possibilité de les étudier. La seconde raison est due à l'absence d'usure à l'emplacement des planchettes de réparation qui ont protégé les traces d'outils primitives. Enfin, et c'est peut-être le plus remarquable, deux des pirogues semblent avoir été abandonnées en cours d'évidement, dont la grande pirogue carolingienne La Soudenais 1 [m] et une pirogue gauloise (Tinfois $3[\mathrm{f}]$ ). Le phénomène est marquant car il s'agit de découvertes rarissimes.

Pour La Soudenais 1, les arguments en faveur d'un abandon de la fabrication en cours sont nombreux. La présence de deux énormes fentes longitudinales sur le fond externe est à relier à la trop forte épaisseur $\mathrm{du}$ fond $(17 \mathrm{~cm}$, alors que 11 à $12 \mathrm{~cm}$ semblent représenter un maximum) et à l'absence de jauges d'épaisseur, pourtant très classiques sur le Brivet, toutes époques confondues. La présence de traces de carbonisation et surtout de très nombreuses traces d'outil sur tout le fond interne de la pirogue indique une absence totale d'usure, difficilement compatible avec une utilisation, même brève (fig. 20). Enfin, l'absence totale d'aménagements ou de réserves, la trop petite profondeur du fond par rapport au can, vont dans le même sens. Morphologiquement, cette pirogue inachevée est à levée sans gradin et il est probable que c'est la forme définitive que voulait lui donner le charpentier.

En ce qui concerne Tinfois 3, nettement moins bien conservée du fait de l'absence de ses flancs, les constatations sont à peu près identiques sauf pour ce qui est de l'épaisseur $\mathrm{du}$ fond, plus proche de la norme habituelle; cependant, les traces d'outils sont partout présentes (fig. 8) et aucune trace d'aménagement particulier n'a été constatée.

Ces deux pirogues possèdent en outre la particularité d'avoir des traces d'outils partant de chacune de leurs extrémités pour se rejoindre vers le centre où un mélange d'orientations s'opère. Pour Tinfois 3, ces détails sont particulièrement visibles, et ici deux outils de tailles différentes ont été utilisés (fig. 21).

Les autres pirogues possédant des traces d'outils visibles sont La Soudenais 4 [af], Le Pré du Crôle 2 [ai] et La Gagnerie d'Abar 1 [ap] (toutes les trois non datées), $L a$ Crôle-Villangeais 1 [a] (pirogue de l'âge du Bronze à tableau arrière), La Crôle-Villaugeais 2 [c] (Hallstatt ou La Tène
Ancienne), La Soudenais 6 [1] ( $\mathrm{IX}^{\mathrm{e}}-\mathrm{x}^{\mathrm{e}}$ siècles), Le Port 4 [n] ( $\mathrm{x}^{\mathrm{e}}$-XII ${ }^{\mathrm{e}}$ siècles; fig. 12 et 20), La Roche-Civant 1 [r] ( $\mathrm{XI}^{\mathrm{e}}-\mathrm{XII}^{\mathrm{e}}{ }^{-}$ siècles), Le Port $1[\mathrm{t}]\left(\mathrm{xI}^{\mathrm{e}}-\mathrm{xII}^{\mathrm{e}}\right.$ siècles; fig. 13) et Le Port $2[\mathrm{u}]$ (xIII ${ }^{\mathrm{e}}$ siècle? fig. 21). En tout, ce sont donc douze embarcations a priori différenciées qui ont livré des traces d'outils : une est du Bronze moyen à final, deux sont gauloises et six sont médiévales.

Si des empreintes de haches ne sont jamais discernables, il est cependant possible que certaines pirogues aient été évidées à l'aide de hachettes à défaut d'herminettes car il n'est pas aisé de distinguer l'une de l'autre sur un simple fragment. Aucune trace de sciage n'a été observée.

Les traces d'outils reconnues sur les fonds ou les flancs (surtout Le Port $2[\mathrm{u}]$ pour ces derniers) ont toutes été exécutées à l'aide d'herminettes à tranchant rectiligne, sinon courbe pour La Soudenais $1[\mathrm{~m}]$ et Tinfois 3 [f] en tout cas, qui a été de plus confectionnée à l'aide d'une herminette à tranchant ébréché. Ces herminettes sont de taille variable, y compris pour une même pirogue (Tinfois 3 conserve les traces d'un outil à tranchant de $7,5 \mathrm{~cm}$, et d'un autre de $3 \mathrm{~cm})$.

Le ciseau à bois a été reconnu dans l'exécution des parties internes du tableau arrière de La Crôle-Villangeais 1 [a]. Forets à cuiller et gouges ont vraisemblablement été utilisés pour réaliser les jauges d'épaisseur, et cela est visible au moins sur La Soudenais 6 [1] (foret) et La Crôle-Villangeais 2 [c] (gouge). Les gournables de ces jauges d'épaisseur, le plus souvent confectionnées dans des bois tendres non identifiés pour l'instant, sont quelquefois biseautées ( $\mathrm{La}$ CrôleVillangeais 2) et toujours taillées à l'aide de couteaux à fer lisse.

Les pirogues possédant des traces d'outils bien préservées sont, parmi les plus connues, celles de Paris-Bercy 1 et 8 , de Cerlier-Heidenweg (Arnold, 1995 b, p. 45 et 75) ou d'Auvernier (Suisse) (Arnold, 1976, p. 75-84). Mais elles ne sont pas très fréquentes du fait de la difficulté de préservation de ces traces. C'est pourquoi les douze exemplaires issus du Brivet représentent un témoignage technologique remarquable, même si ces pirogues sont pour certaines très fragmentaires.

\section{Carbonisation}

La seule pirogue à avoir livré des traces de carbonisation est La Soudenais 1 [m], pirogue sans doute inachevée. Encore une fois, cet abandon précoce et inattendu est source d'informations remarquables car il s'agit de la première embarcation médiévale ayant livré des traces de carbonisation. Ce procédé d'évidement est par contre reconnu pour les pirogues du Néolithique et de l'âge du Bronze (HauteriveChampréveyres en Suisse, Lystrup 1 au Danemark, ParisBercy 2 : Arnold, 1995 a, p. 36, 44, 73). La technique en 


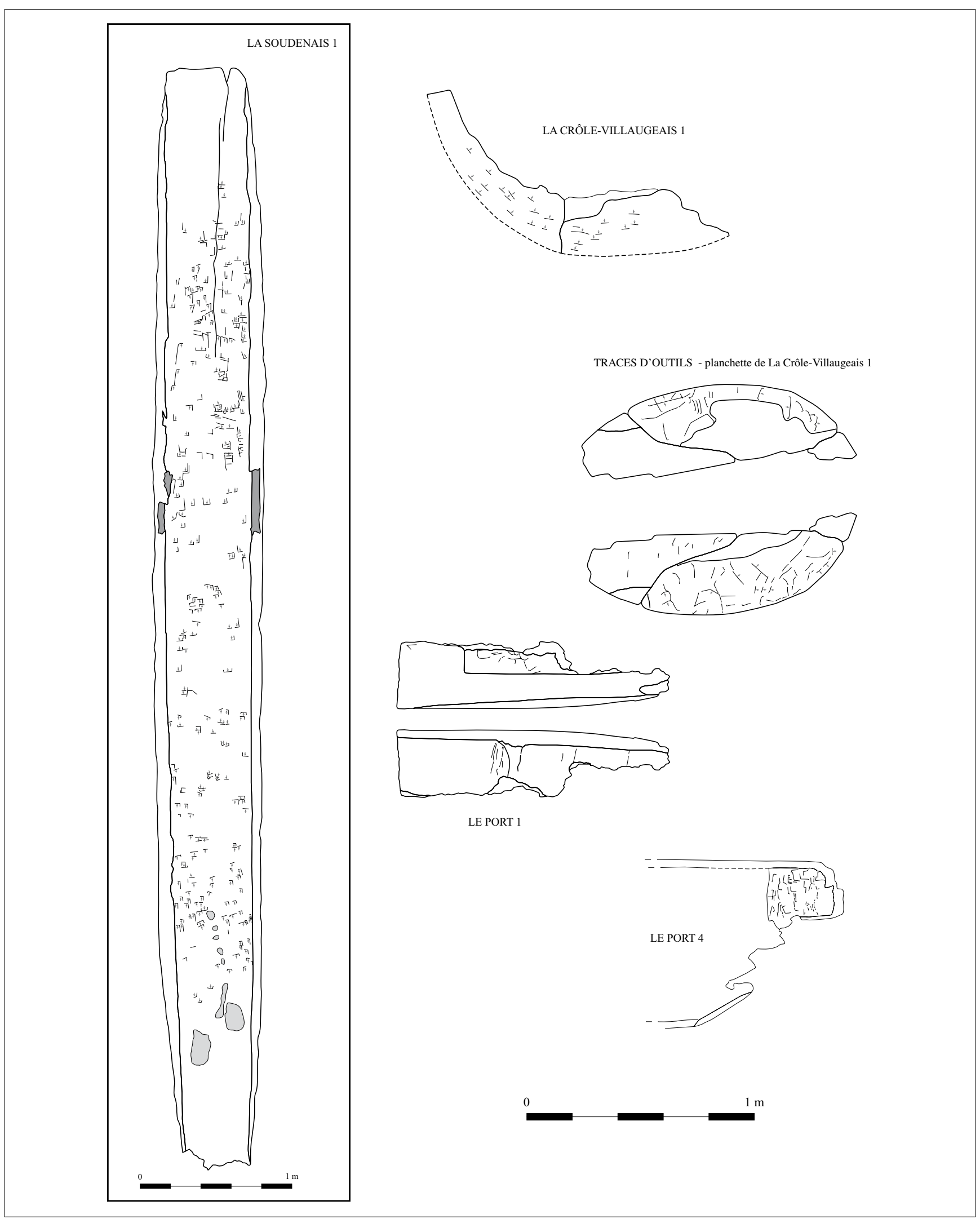

Figure 20 : Relevés de traces d'outils sur quelques pièces significatives (les flèches indiquent le sens de l'impact).

Figure 20 Record of toolmarks on some significant items (arrows mark the direction of impacts). 


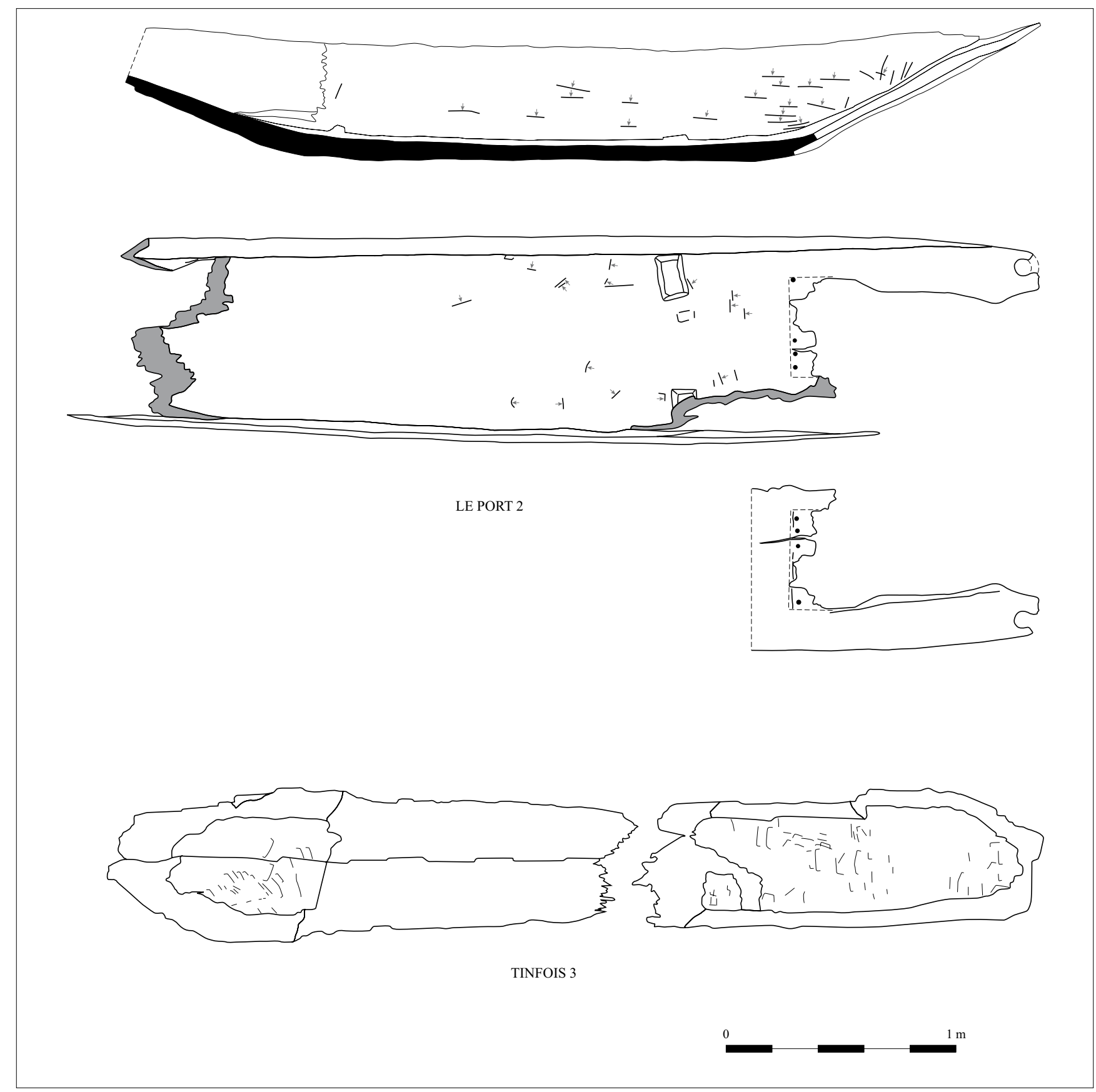

Figure 21 : Relevés de traces d'outils sur quelques pièces significatives (suite).

Figure 21: Record of toolmarks on some significant items (continued).

est simple et consiste à pratiquer une saignée longitudinale en progressant par étapes successives, à l'aide de feux entretenus et contrôlés de bout en bout de la chaîne opératoire. Les finitions sont ensuite faites avec des hachettes ou des herminettes. Les traces relevées sur La Soudenais 1 sont assez disparates mais explicites, d'autant que ces témoins apparaissent aux endroits où l'herminette n'est pas encore passée.

\section{Traces d'utilisation}

\section{Réparations et consolidations}

Nombreux sont les fragments de pirogues qui ont livré des traces de réparation ou de consolidation. Si l'on peut supposer qu'une empreinte de planchette où sont bien conservées des traces d'outils signifie que la pirogue a été consolidée dès l'origine, on est bien en mal de pouvoir le prouver car les 
traces en question peuvent très bien résulter de l'époque de la réparation, des années peut-être après la première mise à flot de l'embarcation.

Le Brivet a livré au moins une pirogue qui n’a pu bénéficier de réparations du fait de l'importance de la fente du bois : il s'agit bien sûr de La Soudenais 1 [m], déjà largement évoquée. Quelques-unes n'ont apparemment pas bénéficié d'aménagements alors qu'elles possèdent des fentes et ont visiblement navigué : L'T̂le Biron 1 [e], Catiho 3 et 4 [ad] et [ae], La Soudenais 7 [ah], Le Prieuré 3 [at], Coët Roz 2 [av], La Sublaire 1 [g], La Crôle-Villangeais 1 et 2 [a] et [c], Marais du Tremble 1 et 2 [am] et [an] Plusieurs autres ont livré des empreintes de planchettes qui, une fois chevillées sur l'esquif (aucune planchette du Brivet n'a été cloutée), permettait d'assurer sa flottabilité, au moins à court terme; ces pirogues sont La Roche-Civant 1 [r], Le Port 1, 2 (fig. 14) et $4[\mathrm{t}]$, [u] et [n], ainsi que La Soudenais $3[\mathrm{~h}]$ qui possède la particularité d'avoir deux entailles de planchettes en visà-vis, l'une située sur la face interne du fond, l'autre sur la face externe. Si malheureusement aucune n'était plus en place sur aucune pirogue (en revanche, les gournables qui les maintenaient sont souvent conservées), plusieurs autres ont pu être recueillies isolément et étudiées (fig. 18). Ces planchettes en chêne sont en fait de simples lattes de bois rectangulaires, peu épaisses et percées d'un nombre très variable de perforations, de trois à six, destinées à recevoir des gournables de tailles diverses. Pour l'instant, seules les embarcations médiévales semblent en avoir été équipées : $\mathrm{La}$ Roche-Civant 1 [r] est datée des $\mathrm{XI}^{\mathrm{e}}$-XII ${ }^{\mathrm{e}}$ siècles, tout comme Le Port $1[\mathrm{t}]$; Le Port 2 [u] est du XIII ${ }^{\mathrm{e}}$ siècle, La Soudenais 3 [h] datant quant à elle de l'époque mérovingienne).

Les traces de calfatage sont plus rares mais se retrouvent dans L'Île Biron $3[\mathrm{w}]$ au niveau d'une fente de part et d'autre d'un trou cylindrique, dans Le Prieuré 3 [at] comme joint entre les parois d'un trou et sa gournable et dans Le Port $2[\mathrm{u}]$ au niveau de certaines fissures. Dans les trois cas, les prélèvements ont montré que des mousses végétales ont été utilisées. De tels calfatages apparaissent régulièrement dans les orifices ou les fentes des monoxyles; c'est le cas de la pirogue $\mathrm{n}^{\circ} 2$ de Saintes par exemple (Grandjean et Rieth, 1992, p. 7-16).

\section{Traces d'usure}

En dehors de fentes et fissures d'origine naturelle, certaines pirogues ont gardé des stigmates de leur utilisation. Dans la plupart des cas, il s'agit de rayures régulières constatées au niveau des levées en partie externe du fond, correspondant aux raclements subis lors des accostages : L'Tle Biron $6[\mathrm{z}]$, Le Prieuré 2 [s], La Gagnerie d'Abar 1 [ap], Le Port 1 et 6 [t] et [j], ainsi que, peut-être, La Soudenais 3 [h] et Le Port 3 [ao]. Quant aux usures dues au frottement de filins, elles ne sont assurées que sur La Gagnerie d'Abar 3 [ar]. La seule embarcation ayant subi un choc ancien lors de son utilisation est La Soudenais 6 [l] qui présente un impact transversal sur sa face inférieure et sous le gradin.

\section{LA MORPHOLOGIE GÉNÉRALE}

Pour ce chapitre, il a semblé logique de s'inspirer de Béat Arnold qui a établi la typologie la plus complète dans le domaine des pirogues monoxyles et des monoxyles assemblés (Arnold, 1995a et b).

\section{Les profils et sections}

Les profils en long des pirogues sont très différents et reflètent parfaitement la diversité des embarcations du Brivet. Les exemplaires filiformes, c'est-à-dire longs mais peu larges, sont principalement représentés par des pirogues comme $L a$ Soudenais 1 [m], La Crôle-Villangeais 2 [c], Le Port 5 [i] ou L'Angle Hermine 2 [p] pour les mieux conservées. Ce sont des pirogues qui ont été confectionnées à partir d'un tronc de grande taille et sans doute entièrement utilisé. D'autres apparaissent plus trapues, c'est-à-dire courtes (moins de $4 \mathrm{~m}$ ) mais larges et épaisses; Tinfois 2 [d] illustre bien ce type d'embarcation. D'autres, enfin, sont courtes et larges mais fines (au moins au niveau des flancs), comme Le Port $2[\mathrm{u}]$ ou La Soudenais $3[\mathrm{~h}]$.

De nombreux types de fonds sont reconnaissables dans la série du Brivet, toujours selon la classification de Béat Arnold (1995 b, p. 11-29).

- Les pirogues à fond aplati et flancs en forme de trapèze ouvert sont représentées par Le Port $2[\mathrm{u}]$, particulièrement bien conservée, mais aussi par La Soudenais 7 [ah], $\mathrm{La}$ Gagnerie d'Abar 2 [aq], L'Île Biron 3 [w] et La Roche-Civant 1 [r]. On peut peut-être y ajouter L'̂́le Biron 1 [e] et $L a$ Soudenais $2[\mathrm{k}]$.

- Les pirogues à fond aplati et flancs cylindriques sont bien représentées par l'île Biron $3[\mathrm{w}]$ et, peut-être, par $\mathrm{La}$ Crôle-Villaugeais 2 [c], La Roche-Civant 2 [ax] et La Gagnerie d'Abar 1 [ap].

- Les pirogues à fond aplati et flancs verticaux apparaissent avec La Soudenais 6 [1], L'Ŷle Biron 6 [z], Catiho 4 [ae], Le Prieuré 1 [as], L'Angle Hermine 2 [p] et, peut-être, Catiho 1 [ab].

- Les fonds aplatis avec des flancs à sections évasées ou en trapèze ouvert ne sont représentés que par une seule embarcation, Tinfois 2 [d].

- Une section de fond aplati puis cylindrique est reconnaissable sur Tinfois 3 [f], qui est peut-être une pirogue inachevée. 
- La Soudenais $1[\mathrm{~m}]$ est la seule à présenter un fond légèrement aplati et des flancs conservant la forme du tronc, mais il s'agit aussi d'une pirogue inachevée.

- La Soudenais 3 [h] et vraisemblablement Le Port 5 [i] appartiennent à un type à fond plat développé et à flancs incurvés.

- Une seule pirogue possède un fond incurvé et des amorces de flancs en évasement : La Soudenais 4 [af].

- Une seule, enfin, présente une section demi-circulaire, La Crôle-Villaugeais 1 [a].

- D'autres, malgré un assez bon état de conservation, sont difficilement classables du fait de l'arrachement des flancs, comme Le Port 4 [n], par exemple.

\section{Les extrémités}

\section{Généralités}

L'hétérogénéité est aussi de rigueur et, en dehors des pirogues à gradins qui représentent un ensemble à peu près cohérent, les extrémités sont quelquefois simplement identifiées par les levées (La Soudenais 1 et $2[\mathrm{~m}]$ et [k], Le Port $4[\mathrm{n}])$, ou par la présence de réserves à la base de la levée ( $\mathrm{La}$ Soudenais $3[\mathrm{~h}]$ ). La majeure partie des extrémités conservées est à bec; toujours d'après les classifications de Béat Arnold (1995 b ), trois familles peuvent être distinguées.

- Les pirogues à bec large sans gradin sont les plus nombreuses, avec des exemplaires particulièrement bien conservés comme La Soudenais 1, 2 et $3[\mathrm{~m}]$, [k] et [h], Le Port 2 et $4[\mathrm{u}]$ et [n], L'Île Biron 5 [y], La Roche-Civant 1 [r]; Le Port 3 [ao] et La Mer de L'Île 2 [ak] font aussi partie de cette catégorie.

- Les pirogues à bec large dotées d'un gradin sont représentées par La Soudenais 6 [1], Coët Roz 2 [av], La Sublaire 1 [g], Le Port 5 [i] (fig. 9), Le Port 6 [j] et, vraisemblablement, La Gagnerie d'Abar 3 [ar].

- Le Pré du Crôle 2 [ai] et, peut-être, Tinfois 3 [f] appartiennent à la catégorie des pirogues à extrémité arrondie, avec gradin dans les deux cas.

- On peut enfin signaler un cas a priori unique, L'Île Biron $I$ [e], à bec peut-être étroit, tandis qu'une autre présente une extrémité en ogive : La Crôle-Villangeais 2 [c].

Les extrémités devraient permettre de distinguer aisément les pirogues, et c'est le cas lorsqu'elles présentent un profil et un plan symétriques, comme La Soudenais 1 [m] par exemple. Mais ce n'est pas une règle intangible car la pirogue découverte à My en 1967 possède une extrémité ogivale, l'autre étant plus arrondie (Bellancourt, 1968).

\section{Gradins et ressauts}

Neuf pirogues possèdent des gradins et des ressauts. Les gradins sont de véritables marches taillées dans une extrémité de l'embarcation (ou les deux), les ressauts n'étant que de simples épaississements réservés au niveau des levées; en fait, les deux systèmes, très proches, séparent nettement le fond de la pirogue de ses levées et permettent à l'occasion de s'asseoir.

La Soudenais 6 [1], Le Pré du Crôle 2 [ai], Coët Roz 2 [av], La Sublaire 1 [g], La Gagnerie d'Abar 3 [ar], Le Port 5 [i] (fig. 9) et Le Port 6 [j] possèdent des extrémités à gradin bien marqué formant en plan un espace plutôt rectangulaire, mais quelquefois elliptique, qui les rapprocheraient de nombre de pirogues médiévales bien connues dans d'autres régions : Gohfeld et Volkach-Astheim en Allemagne (Arnold, 1995 a, p. 124 et 136), Saint-Fraigne en Charente (Rieth, 1991, p. 146-153) pour les formes rectangulaires, Chirbury 1 et Giggleswick Tarn au Royaume-Uni (Arnold, 1995 a, p. 132 et 136) mais aussi la pirogue découverte dans le Brivet en 1967 (Bellancourt, 1968) pour les formes elliptiques ou semi-circulaires. Le Port 4 [n] et La Crôle-Villangeais 2 [c] se limitent à la présence de ressauts.

\section{Les aménagements en partie centrale}

\section{Nervures et renforts}

Éléments structurels de certaines pirogues, les nervures sont des réserves dont la fonction peut être double d'après Béat Arnold. Il peut s'agir soit d'une préparation d'arcasse ou de tableau arrière (voir infra), soit d'un aménagement destiné à mesurer l'épaisseur du fond au moment de l'évidement. L'̂le Biron 1 et 2 [e] et [v], La Gagnerie d'Abar 1 [ap] et surtout $L a$ Crôle-Villangeais 2 [c] sont les quatre pirogues où ce type d'aménagement a pu être observé. La nervure de l'île Biron 1 fait $4,5 \mathrm{~cm}$ de large contre $4 \mathrm{~cm}$ pour l'île Biron 2. Celle de La Gagnerie d'Abar 1 est plus incertaine car il pourrait s'agir aussi d'un renfort très usé. Enfin, $L a$ Crôle-Villangeais 2 est équipée de deux nervures, l'une à la base de la levée, l'autre plus avant vers la partie centrale de la pirogue.

Les renforts sont beaucoup plus imposants que les nervures car leur fonction était de renforcer la coque du bateau. Une seule pirogue possède cet aménagement, isolé dans la partie centrale : Le Port 5 [i].

Les embarcations dotées de ces dispositifs sont très nombreuses, quels que soient les pays ou les époques (Rieth, 1998, p. 70-71). On peut donc s'étonner de leur relative rareté dans la série du Brivet, y compris sur les exemplaires les mieux conservés. 


\section{Tableaux ou arcasses}

L'installation d'un tableau arrière - anciennement dénommé arcasse - peut prendre plusieurs formes, de la simple nervure au système plus complexe de double réserve, et est réalisée au moment de la fabrication de la pirogue. Dans tous les cas, il s'agit d'une technique de consolidation de la poupe. Cet aménagement permet d'insérer une planchette de fermeture et la fonction de l'ensemble de cette installation s'apparente à celle d'un renfort. Cette technique, principalement employée pendant le Néolithique et les périodes protohistoriques, persiste jusqu'au Moyen Âge comme le démontre la pirogue carolingienne de Gueugnon (Bourgogne) (Arnold, 1995 a, p. 130).

L'exemplaire de La Crôle-Villangeais 1 [a], daté de l'âge du Bronze, possède un tableau arrière très bien conservé malgré l'état fragmentaire de l'embarcation. Il s'agit ici d'un système de deux réserves parallèles qui permettent de retenir une planchette dans une rainure centrale biseautée. Près du flanc bâbord, cette rainure s'élargit pour former un aménagement circulaire dont la fonction pourrait avoir été de servir de logement à une pièce de fixation destinée à maintenir la planchette. Le plus remarquable ici, malgré les conditions violentes de repêchage de la pirogue, est la préservation de la planchette dans son compartiment.

Cette dernière, confectionnée dans une essence de bois plus tendre que le chêne et à section biseautée, prend la forme d'une demi-lune, la partie arrondie épousant parfaitement le fond de la pirogue en "demi-tronc circulaire", selon la typologie de B. Arnold (Arnold, 1995 b, p. 11-13). Les réserves et la planchette conservent des traces d'outils parfaitement visibles (fig. 20)

$\mathrm{Si}$ on retrouve tout à fait le même type de double réserve sur la pirogue de Carouge - La Praille (Suisse) (ibidem, p. 5859), datée de l'âge du Bronze ou de l'âge du Fer, la planchette de l'exemplaire du Brivet est quasiment la jumelle de celle recueillie dans la pirogue de Saint-Germain du Plain en Bourgogne, et datée de l'âge du Fer (Dumont et Treffort, 1994, p. 305-319).

Le Brivet a livré une deuxième pirogue à tableau arrière, $\mathrm{La}$ Roche-Civant 2 [ax], mais cette fois très fragmentaire et sans planchette conservée; le type est des plus simples et consiste en une nervure peu profonde destinée à accueillir une fine planchette. Sans plus d'éléments, il nous est difficile d'en assurer la fonction, d'autant que cet élément n'est pas encore daté. Ce type simplifié de tableau s'apparente aux pirogues de Bevaix (Suisse, Néolithique récent), de Paris Bercy 3 ou de ChâlainMarigny (France, respectivement Néolithique récent et âge du Bronze), de Douanne-Gare et de Grandson - Corcelettes (Suisse, âge du Bronze), de Short Ferry (Royaume-Uni, âge du Bronze), de Clifton 1 et 2 (Royaume-Uni, âge du Fer) (Arnold, 1995 a, p. 50, 72-77, 96-97, 108).

\section{Cale-pieds}

Le seul exemplaire à disposer de cale-pieds est Le Port 2 [u] (fig. 14), au nombre de quatre, indiquant par la même occasion le nombre de pagayeurs assis possible (deux, mais il est vrai dans une pirogue de 3,50 m). Ces deux séries de deux cale-pieds sont en fait des réserves de bois en forme de pyramide à quatre pans tronqués. Ils sont assez grossièrement taillés, l'un d'entre eux étant d'ailleurs façonné dans un nœud.

D'autres exemples d'aménagements comparables existent mais il est préférable de les dénommer ressauts : Le Port 4 [n] en est une belle illustration avec deux de ces ressauts latéraux placés en vis-à-vis, ce que l'on retrouve sur La Roche-Civant 1 [r] et Catiho 1 [ab], en moins bien conservé toutefois. S'il est possible qu'il s'agisse là aussi de cale-pieds, rien ne permet de l'affirmer aussi nettement que pour Le Port $2[\mathrm{u}]$ (ces réserves peuvent aussi jouer le rôle de renforts, sinon de support de banc par exemple car elles sont accolées au flanc de la pirogue).

\section{Cloisons}

La Roche-Civant 1 [r] et Le Port 5 [i] sont les seules pirogues qui pourraient avoir bénéficié de cloisons transversales installées en partie centrale du monoxyle. Le conditionnel s'impose car La Roche-Civant 1 est très fragmentaire mais dispose d'une terminaison oblique d'un des flancs, ce qui suggère la possibilité d'un fond situé plus en avant dans l'embarcation. On peut donc imaginer la présence d'un corps central délimité par une cloison transversale. Pour $L e$ Port 5, c'est une membrure transversale située au centre de la pirogue qui encourage une telle hypothèse, mais en ce cas l'érosion du bois après cassure serait très forte : il pourrait aussi s'agir d'un simple renfort.

Les cloisons médianes sont des aménagements classiques et se retrouvent sur nombre d'embarcations européennes et pour toutes époques : Scey sur Saône (Rieth, 1994, p. 155), Châlon Saint-Marcel (Bonnamour, 1992, p. 353-378), Moncey (Passard et alii, 1987, p. 44), Erlach-Heidenweg en Allemagne, Clapton au Royaume-Uni (Arnold, 1995 a, p. 75 et 137), etc. Il peut donc sembler étonnant qu'il y en ait si peu de reconnues dans les pirogues du Brivet, phénomène lié peut-être à l'état de dégradation avancée de nombre d'entre elles (les parties centrales sont souvent absentes).

\section{Les orifices}

Quelques pirogues du Brivet possèdent des orifices volontairement réalisés et destinés à l'amarrage mais, peut-être aussi, à l'ancrage. On les retrouve sur les extrémités, donc $a$ priori sur la proue, bien que les embarcations ayant livré ces informations auraient pu être symétriques et donc disposer 
de tels orifices aux deux extrémités. D'autres sont percés dans les flancs, soit à la base, soit au niveau des cans. Les mieux conservés sont présents sur Le Port 2 [u] mais il s'en retrouve sur Le Port 3 [ao] qui est d'un type analogue à la précédente, peut-être sur L'Île Biron 3 [w] (bien que son orifice soit placé juste au-dessus du bouchain), sur Le Pré $d u$ Crôle 1 [b] (deux orifices au niveau des cans de chaque flanc) et sur La Gagnerie d'Abar 3 [ar] (à la base d'un flanc).

D'autres orifices sont observables, mais cette fois sur le fond de la pirogue et comportant la plupart du temps des gournables, comme sur l'exemplaire publié de Saintes (pirogue 2 : Rieth, 1979). Il faut y voir des jauges d'épaisseur pratiquées lors de la réalisation et destinées à contrôler l'évidement. Quelques pirogues du Brivet possèdent de ces jauges : La Crôle-Villangeais 2 [c] en accueille six parfaitement alignées dans l'axe central de l'embarcation, dont quatre retiennent encore leur gournable; enfin, une de ces jauges est sans doute présente dans l'axe central du fond de L'Angle Hermine 2 [p], sans que la gournable y soit conservée. Ce type d'aménagement se retrouve sur des pirogues britanniques comme celles de Poole (Dorset) ou de Shapwick (Somerset) (Arnold, 1995a, p. 108 et 112) ainsi que sur la pirogue d'Oudon L'Île Neuve, en Loire-Atlantique (Joncheray, 1986, p. 5, fig. 11).

Le Prieuré 1 [as] possède sept trous perforants qui ont la particularité d'être disposées par séries de deux (une seule gournable y est préservée), système que l'on retrouve aussi sur Le Prieuré 2 [s] (six perforations). Ce dispositif a déjà été rencontré sur quelques exemplaires français : Châlon Saint-Marcel en Bourgogne (Bonnamour, 1992, p. 353378), ou Sanguinet - Put Blanc dans les Landes et étrangers : Glastonbury 1 au Royaume-Uni (Arnold, 1995 a, p. 76 et p. 112), mais il demeure peu fréquent.

\section{5. ÉLÉMENTS POUR UNE SYNTHÈSE}

\section{Individualité ou homogénéité des formes?}

De l'exemplaire filiforme à l'individu trapu, les pirogues du Brivet ne se ressemblent pas. Si les tailles, confirmées ou estimées, sont très variables, il n'y a pas véritablement de longues pirogues puisque la plus imposante, et encore s'agitil d'une estimation optimiste, ne devait pas dépasser les $7 \mathrm{~m}$ (La Crôle-Villangeais 2 [c]); la plus courte, Le Port $2[\mathrm{u}]$, atteint difficilement $3,5 \mathrm{~m}$. La moyenne reconnue tourne aux alentours de 4,5 à $5 \mathrm{~m}$ pour des largeurs maximales de $0,80 \mathrm{~m}$ (Tinfois 2 [d] atteint $0,82 \mathrm{~m}$ ), la moyenne générale étant de 0,45 à $0,60 \mathrm{~m}$.

Les embarcations du Brivet sont donc petites comparativement à celles de la Seine, de la Loire ou de Savoie et se rapprochent plutôt des pirogues découvertes dans les îles britanniques. L'explication n'est sans doute pas très difficile à deviner : le Brivet est une petite rivière dont la largeur moyenne ne dépasse pas 10 à $12 \mathrm{~m}$, ce qui rendrait compliqué la manoeuvre de bateaux de plus grande taille. Leurs fréquentes extrémités symétriques et leur petite taille leur confèrent un autre avantage, celui de pouvoir remonter et descendre les étiers qui parcourent les marais avoisinants comme le font les chalands actuels.

Les pirogues du Brivet sont typologiquement très diverses, même lorsqu'elles sont plus ou moins contemporaines. Ainsi, les 21 embarcations datées ([a] à [u]), principalement gauloises et médiévales, sont toutes très différentes bien qu'elles appartiennent quelquefois à des contextes chronologiques très voisins. La période médiévale est particulièrement représentative de cet état de fait : on ne peut pas trouver de similitudes entre les pirogues de La Soudenais 1, 2 et 3, pourtant toutes fabriquées pendant le haut Moyen Âge.

La Soudenais 1 [m] est d'un type courant et on retrouve beaucoup de similarités entre cette embarcation et celles de Noyen-sur-Seine (Mordant et alii, 1993, p. 247), de Scey sur Saône (Rieth, 1994, p. 155), de Port-Berteau (Rieth, 1979, p. 117-144), d'Estreboeuf en France (Arnold, 1985, p. 211222) et même de Massay (Rieth, 1998, p. 65), même si cette dernière prend, en plan, une forme trapézoïdale due à la forme du fût utilisé. À l'étranger, on trouve aussi de remarquables similitudes avec des pirogues comme celles de North Stoke au Royaume-Uni ou de Selvazzano 2 en Italie (Arnold, 1995 b, p. 128-129, 134), une des plus longues d'Europe puisqu'elle atteint près de $16 \mathrm{~m}$. On peut aussi noter que, mis à part la pirogue d'Estreboeuf qui n'est pas datée, tous ces exemplaires sont médiévaux s. $l$. ( (VIII-XVI ${ }^{\mathrm{e}}$ siècles).

Grandes sont aussi les différences entre La Soudenais 1 [m] et Le Port $2[\mathrm{u}]$, séparées d'à peine trois siècles. Inversement, des similitudes dans la morphologie générale semblent apparaître entre des pirogues comme La Soudenais 1 [m], carolingienne, et La Crôle-Villaugeais 2 [c], datée du premier âge du Fer. Avec de telles disparités, parler d'une typologie des pirogues du Brivet serait un leurre ou, pour le moins, une hypothèse très audacieuse. Nous ne retrouvons donc pas ces "séries " constituées par des embarcations très proches morphologiquement comme le démontrent, par exemple, les cinq pirogues de la rivière Mersey, en Angleterre (Lancashire), qui sont cadrées entre les $\mathrm{X}^{\mathrm{e}}$ et $\mathrm{XII}^{\mathrm{e}}$ siècles et de formes très voisines (Arnold, 1995a, p. 144-145).

Pourtant, des critères de rapprochement existent si l'on évacue l'arbre en tant que constituant : la pirogue est en effet le produit d'un arbre court ou long, d'un diamètre restreint ou important et d'une qualité générée par les disponibilités (locales ou non d'ailleurs). Interviennent aussi des facteurs difficilement chiffrables ou évaluables comme la compétence 
des artisans, quelquefois les outils utilisés, voire la destination de ces pirogues.

En faisant abstraction de ces paramètres, des facteurs de rapprochement peuvent être évoqués selon les périodes. Morphologiquement, les pirogues gauloises sont plus imposantes par la masse car plus épaisses, même si elles ont été confectionnées dans un bois sans défaut. Les pirogues médiévales possèdent des flancs plus fins et disposent d'aménagements divers : sur les exemplaires datés, on peut évoquer les orifices d'ancrage, les réserves ou la présence de cale-pieds. Nombre d'exemplaires, à l'heure actuelle non datés, possèdent des aménagements comme des ressauts ou gradins propres a priori aux pirogues médiévales et même à celles du Moyen Âge classique (XI ${ }^{\mathrm{e}}$-XIII ${ }^{\mathrm{e}}$ siècles). L'exception que semble représenter La Soudenais 1 [m] s'explique sans doute par le fait qu'elle soit inachevée.

Les deux pirogues les plus intéressantes au niveau de la typo-chronologie sont finalement les deux extrêmes, $L a$ Crôle-Villaugeais 1 [a] et Le Port 2 [u], datées respectivement de l'âge du Bronze moyen à final et du XIII e siècle. Les deux exemplaires appartiennent tout à fait à leurs époques si l'on se réfère à leurs particularités.

La Crôle-Villaugeais 1, exemplaire à tableau arrière et à fond cylindrique, est caractéristique des pirogues de cette époque reconnues en Suisse, en Angleterre ou en France. Malgré son mauvais état de conservation général, les traces d'outils qui y ont été reconnues sont elles aussi bien évocatrices du matériel utilisé à cette époque (ciseau à bois, herminette).

Le Port $2[\mathrm{u}]$, qui est la pirogue la plus récente du Brivet, est d'une facture soignée malgré l'utilisation d'un bois de piètre qualité et dispose d'aménagements particuliers (orifices, cale-pieds, cans biseautés). Mais surtout, elle est morphologiquement plus proche des barques actuelles, alors qu'il s'agit encore d'un monoxyle; est-on à une période charnière, phase ultime du monoxyle avant le développement de la construction par assemblage ou déjà prototype des chalands de Brière actuels? De telles embarcations " intermédiaires " entre monoxyles et barques assemblées existent en Loire, comme par exemple celle de Courchapon, morphologiquement proche de Le Port 2 mais qui accueille déjà des varangues et est surtout constituée de quatre pièces de bois distinctes et chevillées (Villiers et Sénotier, 1997, p. 17).

\section{La fonction et la durée de vie}

D'après Béat Arnold, les pirogues les plus anciennes, mésolithiques, devaient servir principalement à la pêche. Du fait du développement des échanges à partir du Néolithique, nombre de pirogues ont pu servir au transport de marchandises, en particulier des produits issus de l'agriculture; à ce titre, leur taille, leur masse, évoluent et il n'est plus rare de rencontrer des pirogues dépassant les $10 \mathrm{~m}$ de longueur à partir de l'âge du Bronze.

La pirogue peut en fait servir à tout, à l'instar de ce que l'on voit encore en Afrique ou en Amérique du Sud : transport des biens et des personnes, des marchandises les plus diverses, pêche, chasse, utilisation en bac ou pour faire du cabotage... les activités possibles ne manquent pas (Rieth, 1998, p. 73-74). Il n'y a donc pas de raisons objectives pour que les pirogues du Brivet échappent à cette règle générale, même si quelques nuances sont à apporter. La petite taille (relative) des exemplaires recueillis ne peut permettre d'en faire des bateaux à vocation commerciale, tel un fûtreau voire un blin par exemple (Guériff, 1977, p. 25-33). Par contre, et comme c'était encore le cas avant-guerre avec l'actuel chaland briéron, le transport local de tourbe pour la combustion voire pour la construction est plausible, comme peut l'être le transbordement d'une rive à l'autre ou d'un point d'accostage à un autre des réserves de foin, de paille, de roseaux etc. (Millot, 2004, p. 66-77). En effet, leur largeur restreinte et leur fond le plus souvent plat en font des moyens de locomotion appréciables pour remonter ou descendre les étiers à travers les marais.

Dans ces régions souvent inondables et où la population a toujours été très au contact de l'eau, il est de rigueur d'évoquer la pêche comme un des moyens principaux de subsistance au cours des siècles passés. Le cabotage d'exploitation à exploitation et la traversée d'une rive à l'autre, dans un pays où les passages à pied sec sont rarissimes de nos jours encore (deux ponts et deux passerelles sur près de vingt kilomètres de cours du Brivet) peuvent aussi avoir joué un rôle dans le développement des pirogues.

Plus difficile à estimer est la durée de vie et donc d'utilisation d'une pirogue. Très variable, elle dépend en effet de la qualité du bois utilisé et de la fonction même de l'embarcation. D'autres facteurs d'ordre accidentel peuvent intervenir comme une destruction violente par exemple. Bien entretenue, une pirogue peut avoir une durée de vie s'échelonnant sur deux à trois générations (cette longévité nous est attestée par les données ethnoarchéologiques concernant les pirogues sud-américaines, africaines ou polynésiennes) et les traces d'usure, ainsi que certaines réparations ou consolidations, constatées sur certaines pirogues peuvent signifier une utilisation longue et régulière.

En revanche, certaines pirogues du Brivet semblent ne pas avoir servi du tout, comme La Soudenais 1 [m], ou peut-être Tinfois 3 [f]. D’autres, comme Le Port 2 [u], ont certes été utilisées mais la mauvaise qualité du bois, la fragilité des flancs et la présence encore importante de traces d'outils semble indiquer une durée de vie assez courte. 


\section{Le présent et l'avenir des pirogues du Brivet}

Cette découverte unique a permis de collecter une quantité de vestiges en bois gorgés d'eau tout à fait exceptionnelle qu'il est encore aujourd'hui très difficile de gérer. Par définition, les bois gorgés d'eau doivent être traités rapidement selon des procédés longs et coûteux et il a bien fallu établir des priorités concernant la série du Brivet qui, rappelons-le, comprend plus de cinq cents pièces différenciées. Aujourd'hui, tous les bois sont protégés. Ils l'ont été pendant sept ans dans des caissons spécialement conçus et installés dans un étang de Sainte-Anne sur Brivet et, depuis 2005, dans de nouveaux caissons en résine immergés à Sainte-Luce sur Loire près de Nantes. Trois pirogues sont aujourd'hui restaurées. Il s'agit de La Soudenais $1[\mathrm{~m}]$, Le Port $2[\mathrm{u}]$ et $\mathrm{La}$ Crôle-Villaugeais 1 [a] qui ont intégré ou intègreront bientôt respectivement, et une fois leur préservation assurée par le laboratoire Arc Nucléart (Devals et alii, 2007, p. 113-118), le Musée de Bretagne à Rennes, le Musée des Ducs et le Musée Thomas Dobrée à Nantes.

\section{Les apports de l'opération}

Le nombre d'embarcations rencontrées lors du curage du Brivet, sans doute voisin de cinquante (hypothèse basse 35 exemplaires, hypothèse haute 72 et, à l'heure actuelle 21 exemplaires différenciés sur 22 datations enregistrées) ne sera définitivement résolu qu'à l'obtention de l'intégralité des datations. Mais, finalement, ce problème comptable devient secondaire par rapport aux données issues de cette opération très atypique qui offre une palette remarquable d'informations technologiques et archéologiques même si de nombreuses pirogues nous sont parvenues très détériorées. Ces informations sont complétées par la richesse des datations, des formes et des lieux de découvertes : plus que le nombre, ces faits rendent cette opération et cette collection uniques en France et même en Europe (Arnold, 1995 a et b; Creis et al., 2007).

Plus généralement, les informations offertes par l'étude et la datation des pirogues nous renseignent sur l'existence et la localisation de sites archéologiques à proximité immédiate de la rivière (Devals, 2006). Ces données, encore partielles du fait des nombreuses datations qui n'ont pas encore été effectuées, indiquent d'une part l'existence de plus en plus confirmée de deux importants sites voisins ou juxtaposés, l'un protohistorique, l'autre du haut Moyen Âge, et d'autre part le fait que les pirogues ne semblent pas avoir été abandonnées n'importe où comme on aurait pu l'imaginer au départ. Pour celles qui sont datées en tout cas, il apparaît qu'elles ont coulé au niveau ou à proximité de leur port d'attache que l'on situera soit à Catiho, La Soudenais ou Les
Chatelliers à Drefféac, soit au Port à Sainte-Anne sur Brivet. Et si c'est le cas, il s'agit d'un fait remarquable car il est très rare de pouvoir inscrire des embarcations monoxyles dans un environnement et un contexte historique bien limités et définis.

Les deux pirogues de l'âge du Bronze, celle de la période hallstattienne et les deux exemplaires de La Tène Ancienne, sans aucune ressemblance entre elles, forment un ensemble géographiquement regroupé de part et d'autre des buttes du Port et de Catiho et du secteur appelé "Les Chatelliers", dans une zone où la céramique protohistorique est très dense.

Les embarcations du haut Moyen Âge, particulièrement nombreuses, sont encore plus localisées et s'inscrivent dans un périmètre plus proche de ces buttes (Le Port et Catiho-La Soudenais), à l'exception de L'̂lle Biron 5 [y], découverte plus au nord. Peu d'embarcations médiévales ont été découvertes à proximité du goulet de Pont-Château, place forte médiévale et lieu de passage important depuis l'époque gauloise au moins. Les découvertes faites aux alentours du Port et de La Soudenais sont d'autant plus remarquables que c'est dans ce secteur que se trouve aussi le pont en bois de Catiho (pieux prélevés en attente de datation dendrochronologique). C'est de là aussi que proviennent toutes les armes mérovingiennes et carolingiennes (une douzaine d'exemplaires), de nombreux ossements humains et une importante série céramique des mêmes périodes (voir en note 2 les références des rapports). Avec un point de mouillage, un passage et probablement un habitat doublé d'une nécropole, on est en droit d'imaginer objectivement l'existence d'un important site du haut Moyen Âge en bordure de la rivière (Devals, 2005), dans une région que l'on pense avoir été frontalière entre la Bretagne royale puis ducale et la France mérovingienne et carolingienne (Chédeville, 1984, p. 206, Jouët, 2007, p. 43).

\section{Bibliographie}

Arnold, B., 1976 - La pirogue d'Auvernier-Nord 1975 (Bronze final), contribution à la technologie des pirogues monoxyles préhistoriques, Cahiers d'Archéologie Subaquatique, 5, p. 75-84.

Arnold, B., 1985 - La pirogue de Châlain-Marigny et quelques considérations sur les monoxyles découverts en France, Présentation des collections du Musée de Lons-le-Saunier, 1. Néolithique, Châlain-Clairvaux, fouilles anciennes, Lons-leSaunier, Musée d'Archéologie, p. 211-222.

Arnold, B., 1995a - Pirogues monoxyles d'Europe Centrale, Archéologie Neuchâtelloise, 20, 181 p. 
Arnold, B., 1995b - Pirogues monoxyles d'Europe Centrale, Archéologie Neuchâtelloise, 21, 165 p.

BASTARD, G., 1880 - Saint-Nazaire, son histoire, les découvertes $d u$ bassin de Penhouët, le Portus Brivates des Romains, Nantes, Ed. V. Forest - E. Grimaud, 46 p.

Bellancourt, G., 1968 - Découverte d'une pirogue monoxyle en Loire-Atlantique, Feuillets mensuels de la Société nantaise de Préhistoire, 109, p. 19-22.

Bonnamour, L., 1992 - Fouille d'aménagements médiévaux dans le lit de la Saône au Sud de Châlon, Revue archéologique de l'Est, 43, p. 353-378.

Chédeville, A. et Guillotel, H., 1984 - La Bretagne des Saints et des Rois, Rennes, Ouest-France, 430 p.

Creïs, G, Devals, C. et de Saulce, A., 2007 - La batellerie monoxyle de la Loire et ses affluents dans les régions Centre et Pays de la Loire, in de Saulce, A., Serna, V. et Gallicé, A. (dir.), Aestuaria - Archéologies en Loire, Cordemais, éd. Estuarium, coll. "Fleuves et Archéologie », p. 45-87.

Devals, C., 2005 - Le Brivet, archéologie d'une rivière en Haute Bretagne, vers la reconnaissance d'un grand site du Moyen Âge? Rapportage Archeologische Monumentenzorg, 126, Université d'Amersfoort, Pays-Bas, p. 75-88.

Devals, C., 2006 - Archéologie d'une rivière en Haute Bretagne. Actes du colloque de l'Internationaler Kongress für Unterwasserarchäologie (IKUWA 2), Dir. Hafner Albert, Niffeler Urs et Ruoff Ulrich, Zürich (Suisse), Antiqua, 40, p. 210-215.

Devals, C. et Hiron, C., 2007 - Des pirogues au fil du temps, le Brivet (Loire-Atlantique), in Bernard-Maugiron, H. Coeuré, P., Clermont-Joly, M., Duchêne, J., Vaudaine, P. et Veysseyre, P. (dir.), Sauvé des eaux, le patrimoine archéologique en bois, histoires de fouilles et de restaurations, Grenoble, Arc'Nucléart, CEA, $240 \mathrm{p}$

Dumont, A. et Treffort, J.-M., 1994 - Fouille d'une pirogue monoxyle protohistorique à Saint-Germain du Plain (Saôneet-Loire), Revue archéologique de l'Est, 45-2, p. 305-318.

GuERIFF, F., 1977 - La marine en bois du Brivet, navires et marins de Brière, Le Pouliguen, Atelier J.-M. Pierre, 141 p.

Grandjean, P. et Rieth, E., 1992 - Note relative à la seconde pirogue monoxyle du Pont de Saintonge à Saintes, Revue de la Saintonge et de l'Aunis, 18, p. 7-16.

JonCHERAY, D., 1986 - Les embarcations monoxyles dans la région Pays de la Loire, Études préhistoriques et protohistoriques des Pays de la Loire, 9, 31 p.

Jouet, P. et Delorme, K., 2007 - Atlas historique des pays et terroirs de Bretagne. Morlaix, éd. Skol-Vreizh, 160 p.
DE Kerviler, R., 1877 - L'âge du Bronze et les Gallo-romains à Saint-Nazaire-sur-Loire, Bulletin de la Société archéologique de Nantes et de la Loire-Inférieure, 15 (1876), p. 287-316.

Langouët, L., Garcia, Y. et Lorin, A., 1999 - Anciennes pierres de mouillage retrouvées sur le littoral armoricain, Les Dossiers du Centre de Recherches archéologiques d'Aleth (Ce.R.A.A)., 27, p. 5-24.

Millot, G. (dir.), 2004 - La Brière, pays d'entre terre et mer, Plunéret, Hengoun éditions, $160 \mathrm{p}$.

Mordant, D., Galoyer, A. et Koeniger, J.-C., 1993 - Paléo-environnement et pirogue carolingienne à Noyen-sur-Seine, le Pré aux Boufs (Seine-et-Marne). Bulletin du Groupement archéologique de Seine-et-Marne, 32-34 (1991-1993), p. 229-258.

Passard, F., Urlacher, J.-P., Ginier-Gillet, A., Lambert, G. et LAVIER, C., 1987 - La pirogue monoxyle de Moncey (Doubs), Archeonautica, 7, p. 37-54.

RIETH, E., 1979 - Pirogue monoxyle et port fluvial de Port Berteau, in MAC GraiL, S. (ed.), The archaeology of medieval ships and harbours in Nothern Europe (papers based on those presented to an International Symposium on Boat and Ship Archaeology at Bremerhaven in 1979), Oxford, Hadrian Books (British Archaelogical Reports, International Series 66), p. 117-144.

RiETH, E., 1991 - Traditions de construction monoxyle, monoxyleassemblée et assemblée sur la rivière Charente (France), in Reinders, R. \& Paul, K. (ed.), Carvel construction technique : skeleton-first, shell-first. Fifth International Symposium on Boat and Ship Archaeology, Amsterdam, 1988. Oxford, Oxbow Books (Monographs, 12), p. 146-153.

Rieth, E., 1994 - Deux embarcations monoxyles du Musée des Antiquités nationales : les pirogues de l'île de la Cité, à Paris, et de Scey sur Saône, en Haute-Saône, Antiquités Nationales, 26, p. 150-159.

Rieth, E., 1998 - Des bateaux et des fleuves, archéologie de la batellerie du Néolithique aux Temps Modernes en France, Paris, Errance, $160 \mathrm{p}$.

VIEAU, M., 1982 - Le Chronomètre préhistorique de SaintNazaire. Étude du mobilier archéologique du bassin de Penhouët, Études préhistoriques et protohistoriques des Pays de la Loire, 6, 87 p. + 71 pl.

Villiers, P. et Senotier, A., 1997 - Une histoire de la Marine de Loire, Brinon-sur-Sauldre (Cher), éd. Grandvaux, 216 p.

Visset, L., 1990 - 8000 ans en Brière, Rennes, Ouest-France, $64 \mathrm{p}$. 